\title{
Análise do sistema de patentes no Brasil, no espaço temporal de 2000 a 2018
}

\author{
Analysis of the patent system in Brazil, in the time interval from 2000 to 2018 \\ Análisis del sistema de patentes en Brasil, en el espacio tiempo de 2000 a 2018
}

Recebido: 11/03/2021 | Revisado: 17/03/2021 | Aceito: 10/04/2021 | Publicado: 19/04/2021

Gyzah Amui Barros Pereira

ORCID: http://orcid.org/0000-0002-3661-5168 Universidade Federal do Triângulo Mineiro, Brasil

E-mail: gyzah.barros@uftm.edu.br

Lucas de Aquino Amorim Queiroz

ORCID: http://orcid.org/0000-0002-1547-4394

Universidade Federal do Triângulo Mineiro, Brasil

E-mail: lucas.queiroz@uftm.edu.br

Luciana da Costa e Silva Martins

ORCID: http://orcid.org/0000-0003-3156-7803

Universidade Federal do Triângulo Mineiro, Brasil

E-mail: luciana.martins@uftm.edu.br

Maristela Mendes Aguiar

ORCID: http://orcid.org/0000-0001-7996-2728

Universidade Federal do Triângulo Mineiro, Brasil

E-mail:maristtela.aguiar@uftm.edu.br

Naiara Rosa Macedo

ORCID: http://orcid.org/0000-0001-9105-268X

Universidade Federal do Triângulo Mineiro, Brasil

E-mail: namacedo09@gmail.com

Beatriz Gaydeczka

ORCID: http://orcid.org/0000-0002-2604-6504

Universidade Federal do Triângulo Mineiro, Brasil

E-mail: beatriz.gaydeczka@uftm.edu.br

Mônica Hitomi Okura

ORCID: http://orcid.org/0000-0002-9875-9378

Universidade Federal do Triângulo Mineiro, Brasil

E-mail: monica.okura@uftm.edu.br

Ana Claudia Granato

ORCID: http://orcid.org/0000-0001-6487-1225

Universidade Federal do Triângulo Mineiro, Brasil

E-mail: ana.malpass@uftm.edu.br

Geoffroy Roger Pointer Malpass

ORCID: http://orcid.org/0000-0002-0036-5750

Universidade Federal do Triângulo Mineiro, Brasil

E-mail: geoffroy.malpass@uftm.edu.br

\begin{abstract}
Resumo
Esse trabalho teve como objetivo analisar o sistema de patentes no Brasil, no espaço temporal de 2000 a 2018. Os procedimentos metodológicos consistiram em levantamento de dados das bases do Instituto Nacional da Propriedade Industrial (INPI) e da Organização Mundial da Propriedade Intelectual (World Intellectual Property Organization WIPO), os quais serviram de apoio para a extração das informações para esta pesquisa. O trabalho apresentou uma análise da evolução da propriedade intelectual no Brasil, além de análise comparativa com outros países. Para a pesquisa foram utilizados os modelos de avaliação descritiva, quantitativa e transversal. A partir dos resultados obtidos verificou-se que o percentual dos depósitos de patentes é significativamente maior em relação às concessões; as concessões para os não-residentes são maiores do que para os residentes; dos residentes, as Universidades e as Instituições Públicas são os principais impulsionadores de patentes. O Brasil está entre os maiores escritórios de patentes do mundo. Ainda foi possível observar que a China possui o maior desenvolvimento e crescimento de patentes entre os anos de 2004 a 2018. Como conclusão cabe destacar que o Brasil, ao longo do período analisado, conquistou avanços em relação à Propriedade Intelectual, por meio do fortalecimento das políticas internas, a participação de tratados internacionais, investimentos de multinacionais, e Universidades e Instituições Públicas produtivas, os mecanismos efetivos para essa conquista.
\end{abstract}

Palavras-chave: Patentes; Brasil; Propriedade Industrial; INPI; WIPO. 


\begin{abstract}
This paper aimed to analyze the patent system in Brazil, between 2000 and 2018. The methodological procedures consisted of collecting data from the bases of the National Institute of Industrial Property (INPI) and the World Intellectual Property Organization (World Intellectual Property Organization - WIPO), which served as support for the extraction of information for this study. The work presented an analysis of the evolution of intellectual property in Brazil, in addition to a comparative analysis with other countries. For the study, the models of descriptive, quantitative and transversal evaluation were used. From the results obtained, it was found that the percentage of patent filings is significantly higher in relation to concessions; concessions for non-residents are higher than for residents; of residents, Universities and Public Institutions are the main drivers of patents. Brazil is among the largest patent offices in the world. It was also possible to observe that China has the greatest development and growth of patents between the years 2004 to 2018. As a conclusion, it should be noted that Brazil, over the period analyzed, has made progress in relation to Intellectual Property, through the strengthening of internal policies, participation in international treaties, investments by multinationals, and productive public universities and institutions, the effective mechanisms for this achievement.
\end{abstract}

Keywords: Patents; Brazil; Industrial Property; INPI; WIPO.

\title{
Resumen
}

Este trabajo tuvo como objetivo analizar el sistema de patentes en Brasil, entre 2000 y 2018. Los procedimientos metodológicos consistieron en la recolección de datos de las bases del Instituto Nacional de Propiedad Industrial (INPI) y la Organización Mundial de la Propiedad Intelectual (World Intellectual Property Organization - WIPO), que sirvió de apoyo para la extracción de información para esta investigación. El trabajo presentó un análisis de la evolución de la propiedad intelectual en Brasil, además de un análisis comparativo con otros países. Para la investigación se utilizaron los modelos de evaluación descriptiva, cuantitativa y transversal. De los resultados obtenidos, se encontró que el porcentaje de solicitudes de patentes es significativamente mayor en relación a las concesiones; las concesiones para no residentes son más altas que para residentes; de residentes, universidades e instituciones públicas son los principales impulsores de las patentes. Brasil se encuentra entre las oficinas de patentes más grandes del mundo. También se pudo observar que China tiene el mayor desarrollo y crecimiento de patentes entre los años 2004 a 2018. Como conclusión, cabe señalar que Brasil, durante el período analizado, ha avanzado en materia de Propiedad Intelectual, a través del fortalecimiento de políticas internas, participación en tratados internacionales, inversiones de multinacionales y universidades e instituciones públicas productivas, los mecanismos efectivos para este logro.

Palabras clave: Patentes; Brasil; Propiedad Industrial; INPI; OMPI.

\section{Introdução}

A patente é uma das formas mais antigas de proteção de propriedade intelectual e visa incentivar o desenvolvimento tecnológico, econômico e social. O documento de uma patente descreve e legaliza uma invenção, a qual pode ser explorada somente com a autorização do titular da patente, garantindo assim, os direitos exclusivos para usá-la, por um tempo limitado, em determinado país. Ela é concedida, mediante solicitação, por um órgão governamental e qualquer pessoa física ou jurídica pode depositar um pedido de patente, desde que tenha legitimidade para obtê-la, sendo chamado de depositante ou requerente (OMPI; INPI, 2016). Estudos mostram que patentes são consideradas importantes ferramentas para resguardar os direitos dos inventores, como na área de química (Ferreira, 2018) e são fontes de informações importantes em áreas como a saúde (Silva et al, 2018) e plantas (Sousa et al., 2018).

A Lei da Propriedade Industrial aponta dois tipos de patentes: patente de invenção (PI) e patente modelo de utilidade (MU). As patentes de invenção devem atender aos requisitos de novidade, atividade inventiva e aplicação industrial, já os modelos de utilidade são patenteáveis o objeto de uso prático, ou parte deste, suscetível de aplicação industrial, que apresente nova forma ou disposição, envolvendo ato inventivo, que resulte em melhoria funcional no seu uso ou em sua fabricação. Além dos tipos, essa legislação descreve objetos que não podem ser patenteados, sendo (BRASIL, 1996):
a) descobertas, teorias científicas e métodos matemáticos;
b) concepções puramente abstratas;
c) esquemas, planos, princípios ou métodos comerciais, contábeis, financeiros, educativos, publicitários, de sorteio e de fiscalização; 
d) as obras literárias, arquitetônicas, artísticas e científicas ou qualquer criação estética;

e) programas de computador em si;

f) apresentação de informações;

g) regras de jogo;

h) técnicas e métodos operatórios ou cirúrgicos, bem como métodos terapêuticos ou de diagnóstico, para aplicação no corpo humano ou animal;

i) o todo ou parte de seres vivos naturais e materiais biológicos encontrados na natureza, ou ainda que dela isolados, inclusive o genoma ou germoplasma de qualquer ser vivo natural e os processos biológicos naturais.

Em 1970, foi instituído no Brasil o Instituto Nacional da Propriedade Industrial - INPI, que tem por finalidade principal executar, no âmbito nacional, as normas que regulam a propriedade industrial (BRASIL, 1970). Assim, o processo de depósito e concessão do pedido de patentes procederão pelas seguintes etapas principais (INPI, 2020):

a) após o depósito do pedido no INPI, ele é submetido ao exame formal preliminar e, se considerado propriamente documentado, a data de recepção (protocolo ou entrada no INPI) é considerada a data do depósito;

b) o pedido de patente permanece em sigilo por dezoito meses contados a partir da data de depósito ou da data de sua prioridade mais antiga, caso exista alguma. Após os dezoito meses de sigilo, o pedido é publicado na Revista da Propriedade Industrial (RPI) que é publicada semanalmente no site do INPI. Essa publicação pode ser antecipada a requerimento do depositante, entretanto, isso não acelera o exame técnico. Após a publicação e até o final do exame, terceiros interessados podem submeter documentação para subsidiar o exame;

c) o exame do pedido de patente deve ser requerido pelo depositante ou por terceiros interessados, até o prazo de 36 meses contados da data do depósito. Caso o exame do pedido não seja requisitado, o pedido é arquivado. O exame técnico contém um relatório de busca e parecer relativo à patenteabilidade, adaptação à natureza reivindicada (PI ou MU), necessidade de reformulação ou divisão do pedido e exigências técnicas;

d) a decisão do exame pode ser: indeferimento ou deferimento. No caso do deferimento, o depositante tem 60 dias para pagar para a expedição da carta patente.

Uma vez concedida, a patente de invenção vigora pelo prazo de 20 anos e o modelo de utilidade por 15 anos, contados a partir da data de depósito. No entanto, o prazo de vigência não pode ser inferior a 10 anos para patente de invenção e a sete anos para modelo de utilidade, a contar da data de concessão (INPI, 2020).

Outra organização muito importante na área de propriedade intelectual, no entanto em âmbito internacional, é a Organização Mundial da Propriedade Intelectual (World Intellectual Property Organization - WIPO). A WIPO lidera o desenvolvimento de um sistema internacional de propriedade intelectual equilibrado e eficaz que possibilite inovação e criatividade para o benefício de todos (WIPO, 2017).

Em aplicação internacional, o Brasil é signatário do Tratado de Cooperação em Matéria de Patentes (Patent Cooperation Treaty - PCT) desde abril de 1978. O PCT prevê um procedimento simplificado que permite ao inventor ou depositante requerer e obter patentes em diversos países. Também promove e facilita o intercâmbio de informações técnicas, contidas nos documentos de patente, entre pessoas jurídicas e físicas que exercem atividades em determinada área. A vantagem para um solicitante utilizar o PCT é que, ao preencher uma única solicitação em um escritório de patente, num único idioma, ele obterá uma data internacional de depósito, e essa data de depósito terá efeito em cada um dos países designados. Além disso, o PCT provê um período no qual o solicitante pode decidir se prosseguirá em cada um dos países designados (INPI, 2020; OMPI; INPI, 2016; WIPO, 2001).

Portanto, diante da importância da Propriedade Intelectual para o desenvolvimento do país, especialmente em questões de patentes, esse trabalho teve o intuito de realizar buscas de indicadores nas bases do INPI, no período de 2000 a 
2018, e da WIPO, no período de 2004 a 2018, a fim de realizar um estudo científico e tecnológico das patentes depositadas e concedidas no Brasil. O período estudado na base WIPO é diferente em função de os dados estarem disponíveis apenas a partir de 2004.

\section{Metodologia}

Trata-se de uma pesquisa de delineamento quantitativo do tipo transversal que se utilizou de fontes primárias para obtenção dos dados (Gil, 2017). A metodologia utilizada foi a de mineração de dados, que são aplicadas em sistemas de descobertas de conhecimento em bancos de dados. O objetivo dessas técnicas é extrair informações estratégicas escondidas em grandes bancos de dados pesquisa e da determinação de padrões classificações e associações entre elas (Goebel; Gruenwald, 1999 apud Dias, 2002). As técnicas desenvolvidas foram: a) técnica de associação, que estabelece uma correlação estatística entre atributos de dados e conjuntos de dados; e b) técnica árvore decisão, que trata da hierarquização dos dados baseada na separação de classes e subconjuntos (Dias, 2020).

De maneira geral, nota-se que a grande quantidade de informações nos bancos de dados informatizados pode esconder conhecimentos valiosos e úteis para a tomada de decisão. $\mathrm{O}$ aumento no volume dos dados, associado à crescente demanda por conhecimento novo voltado para decisões estratégicas, tem provocado o interesse crescente em descobrir novos conhecimentos em banco de dados, em especial sobre a produção em Ciência e Tecnologia (Romão, 2002).

Para a extração dos dados do presente estudo (Figura 1), foram consultados relatórios disponibilizados nos sites das bases INPI (https://www.gov.br/inpi/pt-br/central-de-conteudo/estatisticas) e WIPO (https://ipportal.wipo.int/). A Figura 1 apresenta a sequência de passos desenvolvida em cada base para obtenção dos dados. Cabe destacar que em cada base o procedimento de busca é distinto. O recorte temporal foi delimitado de 2000 a 2018 . A operacionalização das variáveis considerou a quantidade de depósitos nas seguintes categorias: tipologia (Patente de Invenção, Modelo de Utilidade e Certificado de Adição); concessão; origem (residentes, não residentes); países depositantes; natureza jurídica (pessoa física ou jurídica); via (direta ou PCT); campo tecnológico (IPC). Para a análise dos resultados obtidos foram realizados testes descritivos (média e frequência) e estatísticos.

Figura 1: Fluxograma do passo-a-passo utilizado no levantamento dos dados.
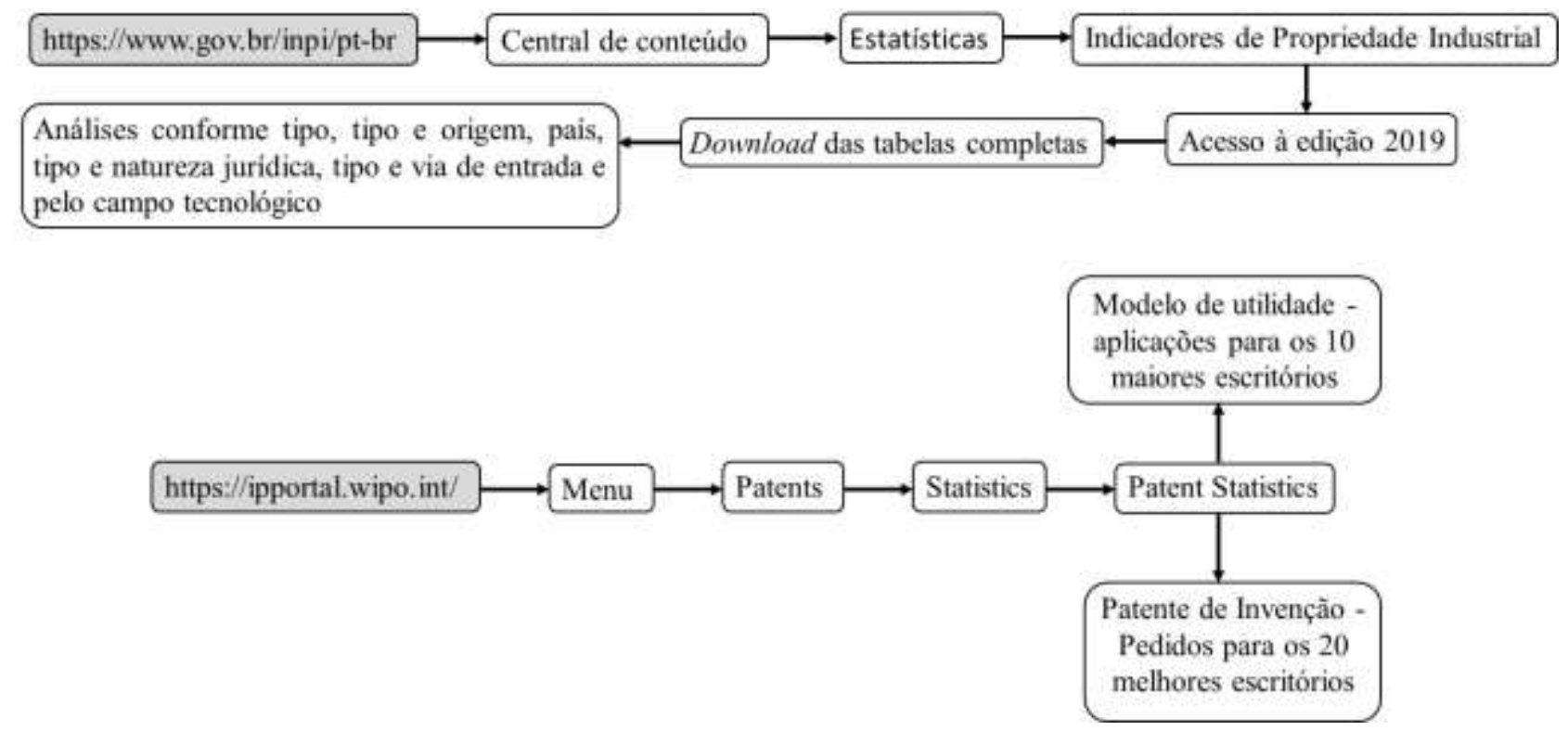

Fonte: Autores (2021). 


\section{Resultados e Discussão (pode ser separado ou junto) (fonte TNR 12 - alinhado esquerda)}

\subsection{Análise dos dados do INPI}

\subsubsection{Por tipo}

No Brasil, as patentes são classificadas em três tipos: patente de invenção (PI), modelo de utilidade (MU) e certificado de adição (CA). Os conceitos e definições da patente de invenção e do modelo de utilidade foram abordados anteriormente. Dessa forma, cabe nortear o conceito de certificado de adição. Segundo o INPI, o CA é aplicado a aperfeiçoamentos ou desenvolvimentos no objeto da invenção, mesmo que destituído de atividade inventiva, servindo de instrumento acessório à patente de invenção e cobrindo os mesmos prazos desta (INPI, 2020).

Outro aspecto relevante sobre esse tipo de patente é a territorialidade, uma vez que sua concessão é válida apenas no território da nação onde foi depositada. Embora o Brasil seja signatário em tratados internacionais, para que a patente seja validada, a parte interessada deverá submeter um novo processo na entidade internacional correspondente. Essa regra vale também para as patentes estrangeiras que deverão ser reconhecidas mediante depósito no INPI. As Tabelas 1 e 2, abordam os três tipos de patentes, tanto no aspecto de depósito quanto no de concessão, no período de 2000 a 2018 , no Brasil.

Tabela 1: Depósito de patente por Tipo, no período de 2000 a 2018, no Brasil.

\begin{tabular}{l|rrrr|}
\hline \multirow{2}{*}{ Ano } & \multicolumn{2}{|c|}{ Tipo } & \multirow{2}{*}{ Total } \\
\cline { 2 - 3 } & PI & MU & \multicolumn{1}{c}{ CA } & \\
\hline 2000 & 17444 & 3332 & 78 & 20854 \\
2001 & 17907 & 3558 & 90 & 21555 \\
2002 & 16685 & 3546 & 103 & 20334 \\
2003 & 16410 & 3640 & 126 & 20176 \\
2004 & 16707 & 3602 & 122 & 20431 \\
2005 & 18486 & 3243 & 123 & 21852 \\
2006 & 19851 & 3181 & 120 & 23152 \\
2007 & 21656 & 3044 & 140 & 24840 \\
2008 & 23120 & 3392 & 129 & 26641 \\
2009 & 22383 & 3378 & 124 & 25885 \\
2010 & 24986 & 3005 & 108 & 28099 \\
2011 & 28658 & 3134 & 89 & 31881 \\
2012 & 30435 & 3010 & 124 & 33569 \\
2013 & 30877 & 3035 & 134 & 34046 \\
2014 & 30341 & 2734 & 106 & 33181 \\
2015 & 30217 & 2719 & 106 & 33042 \\
2016 & 28009 & 2937 & 74 & 31020 \\
2017 & 25658 & 2918 & 91 & 28667 \\
2018 & 24857 & 2587 & 107 & 27551 \\
\hline
\end{tabular}

Fonte: INPI (2020). 
Research, Society and Development, v. 10, n. 4, e50210413791, 2021

(CC BY 4.0) | ISSN 2525-3409 | DOI: http://dx.doi.org/10.33448/rsd-v10i4.13791

Tabela 2: Concessão de patente por Tipo, no período de 2000 a 2018, no Brasil.

\begin{tabular}{r|rrrrr}
\hline \multirow{2}{*}{ Ano } & \multicolumn{3}{|c|}{ Tipo } & \multirow{2}{*}{ Total } \\
\cline { 2 - 4 } & PI & MU & CA & \\
\hline 2000 & 6268 & 426 & 1 & 6695 \\
2001 & 3298 & 326 & 3 & 3627 \\
2002 & 4430 & 359 & 3 & 4792 \\
2003 & 4277 & 476 & 13 & 4766 \\
2004 & 2265 & 269 & 8 & 2542 \\
2005 & 2473 & 369 & 16 & 2858 \\
2006 & 2510 & 276 & 15 & 2801 \\
2007 & 1650 & 200 & 13 & 1863 \\
2008 & 2522 & 290 & 18 & 2830 \\
2009 & 2790 & 357 & 16 & 3163 \\
2010 & 3251 & 362 & 10 & 3623 \\
2011 & 3451 & 349 & 13 & 3813 \\
2012 & 2835 & 292 & 11 & 3138 \\
2013 & 2974 & 347 & 6 & 3327 \\
2014 & 2751 & 366 & 6 & 3123 \\
2015 & 3411 & 479 & 5 & 3895 \\
2016 & 4195 & 564 & 12 & 4771 \\
2017 & 5450 & 788 & 12 & 6250 \\
2018 & 9968 & 1098 & 24 & 11090 \\
\hline
\end{tabular}

Fonte: INPI (2020).

Conforme análise das Tabelas 1 e 2, pode-se inferir que do total dos três tipos de depósitos de patentes (27.551 pedidos de patentes); aproximadamente 90,21\% refere-se à PI; 9,38\% refere-se ao MU e apenas 0,38\% refere-se ao CA. Essa regra se repete também na concessão, pois a porcentagem é bastante semelhante, ou seja, do total das concessões (11.090 concessões); aproximadamente $89,88 \%$ refere-se à PI; 9,90\% ao MU e 0,21\% ao CA. Dessa forma, percebe-se a predominância de depósito e concessão pela patente de invenção.

Outro aspecto bastante notório é em relação à quantidade de patentes que são depositadas versus à quantidade de patentes, que de fato, são concedidas. Dos 27.551 pedidos de patentes depositados, apenas 11.090 foram concedidos, o que corresponde cerca de 40,25\%, ou seja, menos da metade dos pedidos foram concedidos.

Também pode-se notar aspectos bastante interessantes: no ano de 2007, na Tabela 2, houve uma queda significativa nos três tipos de patentes, e nessa mesma tabela, no ano de 2018 em relação ao de 2017 , houve quase o dobro de concessão de patentes.

\subsubsection{Por tipo e por origem}

Segundo definição do Ministério da Ciência e Tecnologia da Inovação (MCTI, 2019), a origem do depositante pode ser residente e não-residente. É considerada residente a pessoa que mora no Brasil, com obrigações tributárias e cadastrais, é aquela que reside no país em caráter definitivo; ao passo que a pessoa não-residente é aquela que não reside em caráter permanente no Brasil. A abordagem que o INPI fez em relação ao conceito de origem, foi: residente, quando o responsável pelo depósito obrigatoriamente reside no Brasil, cabendo ressaltar que se incluem nesse conceito as empresas estrangeiras com filial legalmente constituída no país, e não residente, caracterizados por pessoa física ou jurídica sem domicílio no país e que realizam registros por meio de PCT ou diretamente no escritório brasileiro. 
Khan \& Dernis (2006) compreendem que o país de residência do inventor, ou seja, a origem da patente, reflete as atividades inovativas. Segundo a FAPESP (2011), as patentes de não residentes indicam o interesse que um determinado país, como o Brasil, representa para empresas de outros países.

As Tabelas 3 e 4 mostram a relação de depósito e concessão de patentes dos residentes e não residentes no país atrelado aos três tipos de patentes, no período de 2000 a 2018, no Brasil.

Segundo análise da Tabela 3, têm-se os indicadores: depósito de patentes por origem, ou seja, a classificação dos residentes e não-residentes no país combinado com o tipo patente. Considerando-se primeiramente a origem como residente, tem-se que as PI representam cerca de 65,80\%. Em termos quantitativos esse número é de 4.980 do total de 7.569 depósitos; para o tipo MU o depósito cai para 2.493 depósitos, representando cerca de 32,93\% e para o tipo CA tem-se cerca de 1,3\%.

Por outro lado, os depósitos de não-residentes apontam um aumento em relação ao tipo PI, pois o total de depósitos pelos não-residentes é 19.982 e a maciça porcentagem destinada à PI representa cerca de 99,47\% (19.877 depósitos); para o tipo MU, tem-se apenas o quantitativo de 94 depósitos, o que representa cerca $0,47 \%$ e o restante representa o tipo CA $(0,05 \%)$. 
Tabela 3: Depósitos de Patentes por Tipo e por Origem (Residente ou Não-residente), no período de 2000 a 2018 , no Brasil.

\begin{tabular}{|c|c|c|c|c|c|c|c|c|c|c|c|c|c|}
\hline \multirow{3}{*}{ Ano } & \multicolumn{12}{|c|}{ Tipo } & \multirow{3}{*}{ Total } \\
\hline & \multicolumn{3}{|c|}{ PI } & \multicolumn{3}{|c|}{ MU } & \multicolumn{3}{|c|}{ CA } & \multicolumn{3}{|c|}{ Total } & \\
\hline & $\begin{array}{c}\text { Resident } \\
\text { e }\end{array}$ & $\begin{array}{c}\text { Não- } \\
\text { residente }\end{array}$ & N.A. ${ }^{(1)}$ & $\begin{array}{c}\text { Resident } \\
\text { e }\end{array}$ & $\begin{array}{c}\text { Não- } \\
\text { residente }\end{array}$ & N.A. ${ }^{(1)}$ & $\begin{array}{c}\text { Resident } \\
\text { e }\end{array}$ & $\begin{array}{c}\text { Não- } \\
\text { residente }\end{array}$ & N.A. ${ }^{(1)}$ & $\begin{array}{c}\text { Resident } \\
\text { e }\end{array}$ & $\begin{array}{c}\text { Não- } \\
\text { residente }\end{array}$ & N.A. ${ }^{(1)}$ & \\
\hline 2000 & 3178 & 14080 & 186 & 3200 & 94 & 38 & 71 & 7 & 0 & 6449 & 14181 & 224 & 20854 \\
\hline 2001 & 3439 & 14389 & 79 & 3448 & 97 & 13 & 82 & 8 & 0 & 6969 & 14494 & 92 & 21555 \\
\hline 2002 & 3476 & 13192 & 17 & 3478 & 59 & 9 & 98 & 5 & 0 & 7052 & 13256 & 26 & 20334 \\
\hline 2003 & 3861 & 12543 & 6 & 3584 & 55 & 1 & 119 & 7 & 0 & 7564 & 12605 & 7 & 20176 \\
\hline 2004 & 4041 & 12661 & 5 & 3545 & 57 & 0 & 115 & 7 & 0 & 7701 & 12725 & 5 & 20431 \\
\hline 2005 & 4047 & 14408 & 31 & 3182 & 56 & 5 & 117 & 6 & 0 & 7346 & 14470 & 36 & 21852 \\
\hline 2006 & 3957 & 15875 & 19 & 3125 & 55 & 1 & 112 & 7 & 1 & 7194 & 15937 & 21 & 23152 \\
\hline 2007 & 4193 & 17445 & 18 & 3007 & 37 & 0 & 126 & 14 & 0 & 7326 & 17496 & 18 & 24840 \\
\hline 2008 & 4268 & 18830 & 22 & 3327 & 62 & 3 & 116 & 13 & 0 & 7711 & 18905 & 25 & 26641 \\
\hline 2009 & 4262 & 18094 & 27 & 3332 & 41 & 5 & 115 & 9 & 0 & 7709 & 18144 & 32 & 25885 \\
\hline 2010 & 4225 & 20733 & 28 & 2916 & 87 & 2 & 103 & 5 & 0 & 7244 & 20825 & 30 & 28099 \\
\hline 2011 & 4705 & 23925 & 28 & 3009 & 124 & 1 & 83 & 6 & 0 & 7797 & 24055 & 29 & 31881 \\
\hline 2012 & 4798 & 25601 & 36 & 2894 & 116 & 0 & 116 & 7 & 1 & 7808 & 25724 & 37 & 33569 \\
\hline 2013 & 4955 & 25921 & 1 & 2892 & 143 & 0 & 124 & 10 & 0 & 7971 & 26074 & 1 & 34046 \\
\hline 2014 & 4657 & 25684 & 0 & 2639 & 95 & 0 & 98 & 8 & 0 & 7394 & 25787 & 0 & 33181 \\
\hline 2015 & 4640 & 25577 & 0 & 2607 & 112 & 0 & 97 & 9 & 0 & 7344 & 25698 & 0 & 33042 \\
\hline 2016 & 5199 & 22810 & 0 & 2815 & 122 & 0 & 68 & 6 & 0 & 8082 & 22938 & 0 & 31020 \\
\hline 2017 & 5480 & 20178 & 0 & 2843 & 75 & 0 & 81 & 10 & 0 & 8404 & 20263 & 0 & 28667 \\
\hline 2018 & 4980 & 19877 & 0 & 2493 & 94 & 0 & 96 & 11 & 0 & 7569 & 19982 & 0 & 27551 \\
\hline
\end{tabular}

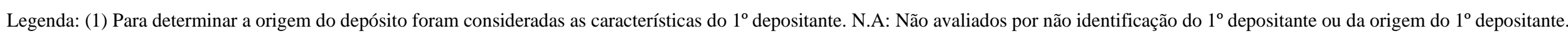
Fonte: INPI (2020). 
Research, Society and Development, v. 10, n. 4, e50210413791, 2021

(CC BY 4.0) | ISSN 2525-3409 | DOI: http://dx.doi.org/10.33448/rsd-v10i4.13791

Tabela 4: Concessão de Patentes por Tipo e por Origem (Residente ou Não-residente), no período de 2000 a 2018, no Brasil.

\begin{tabular}{|c|c|c|c|c|c|c|c|c|c|c|c|c|c|}
\hline \multirow{3}{*}{ Ano } & \multicolumn{12}{|c|}{ Tipo } & \multirow{3}{*}{ Total } \\
\hline & \multicolumn{3}{|c|}{ PI } & \multicolumn{3}{|c|}{ MU } & \multicolumn{3}{|c|}{ CA } & \multicolumn{3}{|c|}{ Total } & \\
\hline & $\begin{array}{c}\text { Resident } \\
\text { e }\end{array}$ & $\begin{array}{c}\text { Não- } \\
\text { residente }\end{array}$ & N.A. ${ }^{(1)}$ & $\begin{array}{c}\text { Resident } \\
\text { e }\end{array}$ & $\begin{array}{l}\text { Não- } \\
\text { residente }\end{array}$ & N.A. ${ }^{(1)}$ & $\begin{array}{c}\text { Resident } \\
\text { e }\end{array}$ & $\begin{array}{l}\text { Não- } \\
\text { residente }\end{array}$ & N.A. ${ }^{(1)}$ & $\begin{array}{c}\text { Resident } \\
\text { e }\end{array}$ & $\begin{array}{l}\text { Não- } \\
\text { residente }\end{array}$ & N.A. ${ }^{(1)}$ & \\
\hline 2000 & 649 & 5567 & 52 & 402 & 23 & 1 & 1 & & 0 & 1052 & 5590 & 53 & 6695 \\
\hline 2001 & 380 & 2884 & 34 & 312 & 12 & 2 & 3 & & 0 & 695 & 2896 & 36 & 3627 \\
\hline 2002 & 337 & 4004 & 89 & 338 & 20 & 1 & 2 & & 0 & 677 & 4025 & 90 & 4792 \\
\hline 2003 & 405 & 3784 & 88 & 444 & 27 & 5 & 11 & & 0 & 860 & 3813 & 93 & 4766 \\
\hline 2004 & 279 & 1952 & 34 & 252 & 12 & 5 & 8 & & 0 & 539 & 1964 & 39 & 2542 \\
\hline 2005 & 248 & 2204 & 21 & 343 & 21 & 5 & 13 & & 0 & 604 & 2228 & 26 & 2858 \\
\hline 2006 & 231 & 2243 & 36 & 256 & 14 & 6 & 10 & & 0 & 497 & 2262 & 42 & 2801 \\
\hline 2007 & 198 & 1444 & 8 & 185 & 12 & 3 & 10 & & 0 & 393 & 1459 & 11 & 1863 \\
\hline 2008 & 234 & 2283 & 5 & 277 & 11 & 2 & 17 & & 0 & 528 & 2295 & 7 & 2830 \\
\hline 2009 & 340 & 2440 & 10 & 337 & 20 & 0 & 14 & & 0 & 691 & 2462 & 10 & 3163 \\
\hline 2010 & 313 & 2931 & 7 & 343 & 18 & 1 & 10 & & 0 & 666 & 2949 & 8 & 3623 \\
\hline 2011 & 380 & 3064 & 7 & 332 & 17 & 0 & 13 & & 0 & 725 & 3081 & 7 & 3813 \\
\hline 2012 & 363 & 2467 & 5 & 281 & 10 & 1 & 10 & & 0 & 654 & 2478 & 6 & 3138 \\
\hline 2013 & 384 & 2584 & 6 & 338 & 9 & 0 & 6 & & 0 & 728 & 2593 & 6 & 3327 \\
\hline 2014 & 374 & 2371 & 6 & 349 & 15 & 2 & 6 & & 0 & 729 & 2386 & 8 & 3123 \\
\hline 2015 & 462 & 2945 & 4 & 466 & 13 & 0 & 5 & & 0 & 933 & 2958 & 4 & 3895 \\
\hline 2016 & 528 & 3655 & 12 & 550 & 14 & 0 & 10 & & 0 & 1088 & 3671 & 12 & 4771 \\
\hline 2017 & 714 & 4724 & 12 & 764 & 22 & 2 & 12 & & 0 & 1490 & 4746 & 14 & 6250 \\
\hline 2018 & 1066 & 8878 & 24 & 1052 & 41 & 5 & 20 & & 0 & 2138 & 8923 & 29 & 11090 \\
\hline
\end{tabular}

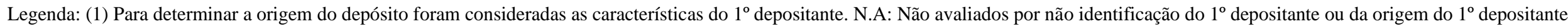
Fonte: INPI (2020). 
Research, Society and Development, v. 10, n. 4, e50210413791, 2021

(CC BY 4.0) | ISSN 2525-3409 | DOI: http://dx.doi.org/10.33448/rsd-v10i4.13791

Comparando o total de depósitos, entre os anos de 2000 até 2018 (27.551), pode-se notar que 72,52\% é derivado dos não-residentes. No que se refere às características dos responsáveis pelos depósitos de patentes, segundo Ribeiro, Paiva \& Loureiro (2010), as patentes dos não-residentes são, predominantemente, depositadas por empresas, particularmente, grandes multinacionais. Por outro lado, os depositantes das patentes de residentes são, em geral, as Universidades ou as Instituições Públicas de Ensino e Pesquisa. Dessa forma, pode-se vislumbrar a importância das grandes multinacionais em relação aos investimentos que são produzidos no país que se instalam.

Segundo Campos \& Denig (2010, p. 112), analisando a correlação entre o número de depósitos feitos por residentes e não residentes, observa-se a seguinte observação dos autores:

[...] a maior parte dos depósitos de patentes feitos no Brasil vem de outros países. A justificativa é que isso acontece para fins de exportação, ou seja, outros países estão conquistando o mercado brasileiro. E, consequentemente, o número de depósitos de patentes feitos por brasileiros é bastante inferior aos não residentes.

Comparando, os depósitos (Tabela 3) com as concessões (Tabela 4), pode-se notar uma queda percentual em relação ao tipo PI, pois em relação aos depósitos que representavam cerca de 99,47\%, houve uma queda drástica para 49,85\%. Em relação ao tipo MU, houve um aumento para 49,20\%. Já em relação à concessão do tipo CA tem-se apenas 20 depósitos, o que representa cerca $0,93 \%$.

Para as concessões de não-residentes combinado com o tipo de patente, tem-se os resultados quantitativos de 8.878 patentes concedidas entre 2000 a 2018, sendo que a maciça porcentagem 99,49\%, foi destinada à PI, para o tipo MU tem-se apenas cerca $0,45 \%$ e o restante, $0,04 \%$, representa o tipo CA.

\subsubsection{Por país}

As Tabelas 5 e 6 representam os dez países que tiveram mais depósitos e concessões de patentes do tipo PI, no período de 2000 a 2018, respectivamente. Segundo as Tabelas 5 e 6, o país que teve mais depósito e concessão de patentes do tipo PI no período estudado foram os Estados Unidos, representando aproximadamente 36,2\% entre os dez países que mais possuem depósitos e concessões. 
Research, Society and Development, v. 10, n. 4, e50210413791, 2021

(CC BY 4.0) | ISSN 2525-3409 | DOI: http://dx.doi.org/10.33448/rsd-v10i4.13791

Tabela 5: Dez países que tiveram mais depósitos do Tipo Patente de Invenção - PI, no período de 2000 a 2018, no Brasil.

\begin{tabular}{|c|c|c|c|c|c|c|c|c|c|c|c|}
\hline \multirow{2}{*}{ País } & \multirow{2}{*}{ Sigla do País } & \multicolumn{10}{|c|}{ Ano } \\
\hline & & 2000 & 2001 & 2002 & 2003 & $\ldots$ & 2015 & 2016 & 2017 & 2018 & Total por país \\
\hline Estados Unidos & US & 6190 & 6062 & 5431 & 4946 & $\ldots$ & 10267 & 9100 & 7949 & 7578 & 139285 \\
\hline Brasil & BR & 3178 & 3439 & 3476 & 3861 & $\ldots$ & 4640 & 5199 & 5480 & 4980 & 82361 \\
\hline Alemanha & $\mathrm{DE}$ & 2048 & 2237 & 1944 & 1837 & $\ldots$ & 2500 & 2219 & 1910 & 1970 & 43000 \\
\hline Japão & $J P$ & 713 & 871 & 755 & 714 & $\cdots$ & 2143 & 1829 & 1717 & 1688 & 28591 \\
\hline França & FR & 1049 & 955 & 931 & 921 & $\ldots$ & 1709 & 1452 & 1355 & 1214 & 25660 \\
\hline Suíça & $\mathrm{CH}$ & 535 & 547 & 593 & 731 & $\ldots$ & 1368 & 1347 & 1066 & 1104 & 20279 \\
\hline Holanda & NL & 472 & 536 & 600 & 495 & $\ldots$ & 1259 & 965 & 854 & 833 & 15724 \\
\hline Reino Unido & GB & 499 & 485 & 432 & 464 & $\ldots$ & 730 & 697 & 657 & 741 & 11518 \\
\hline China & $\mathrm{CN}$ & 25 & 14 & 36 & 29 & $\ldots$ & 737 & 799 & 676 & 648 & 6113 \\
\hline Itália & IT & 350 & 369 & 389 & 461 & $\ldots$ & 695 & 640 & 601 & 604 & 10452 \\
\hline \multicolumn{2}{|c|}{ Total por ano } & 15059 & 15515 & 14587 & 14459 & $\ldots$ & 26048 & 24247 & 22265 & 21360 & 382983 \\
\hline
\end{tabular}

Fonte: Adaptado de INPI (2020).

Tabela 6: Dez países que tiveram mais concessões do Tipo Patente de Invenção - PI, no período de 2000 a 2018 , no Brasil.

\begin{tabular}{|c|c|c|c|c|c|c|c|c|c|c|c|}
\hline \multirow{2}{*}{ País } & \multirow{2}{*}{ Sigla do País } & \multicolumn{10}{|c|}{ Ano } \\
\hline & & 2000 & 2001 & 2002 & 2003 & $\ldots$ & 2015 & 2016 & 2017 & 2018 & Total por país \\
\hline Estados Unidos & US & 2258 & 1156 & 1665 & 1569 & $\ldots$ & 1044 & 1290 & 1527 & 2872 & 22553 \\
\hline Alemanha & $\mathrm{DE}$ & 871 & 464 & 580 & 613 & $\ldots$ & 379 & 460 & 611 & 1112 & 9333 \\
\hline Brasil & BR & 649 & 380 & 337 & 405 & $\ldots$ & 462 & 528 & 714 & 1066 & 7885 \\
\hline França & $\mathrm{FR}$ & 346 & 200 & 291 & 296 & $\ldots$ & 243 & 323 & 436 & 800 & 5060 \\
\hline Japão & $J P$ & 289 & 122 & 156 & 206 & $\cdots$ & 200 & 315 & 442 & 931 & 4525 \\
\hline Suíça & $\mathrm{CH}$ & 254 & 113 & 121 & 131 & $\ldots$ & 172 & 199 & 283 & 511 & 3259 \\
\hline Itália & IT & 205 & 94 & 140 & 152 & $\cdots$ & 107 & 123 & 198 & 380 & 2474 \\
\hline Reino Unido & GB & 252 & 140 & 159 & 160 & $\ldots$ & 82 & 98 & 131 & 235 & 2121 \\
\hline Suécia & SE & 216 & 112 & 266 & 119 & $\ldots$ & 92 & 107 & 106 & 273 & 2046 \\
\hline \multicolumn{2}{|c|}{ Total por ano } & 5626 & 2898 & 3904 & 3767 & $\ldots$ & 2968 & 3657 & 4717 & 8584 & 62279 \\
\hline
\end{tabular}

Fonte: Adaptado de INPI (2020). 
Para depósitos, o Brasil ficou classificado em segundo lugar e a Alemanha em terceiro. Já para concessão, a Alemanha ficou classificada em segundo e o Brasil em terceiro. Comparando os países que constam nas duas Tabelas 5 e 6, apenas a China não ficou classificada entre os dez países que tiveram mais concessões e Suécia não consta entre os dez países que mais fizeram depósitos. Portanto, com exceção desses dois países e considerando-se os demais, no total foram 376.870 depósitos e 60.233 concessões, o que representa que dos depósitos $16 \%$ de patentes do tipo PI foram concedidas.

As Tabelas 7 e 8, representam os dez países que tiveram mais depósitos e concessões de patentes do tipo de Modelo de Utilidade - MU, no período de 2000 a 2018, respectivamente. Para as patentes do tipo MU, de acordo com as Tabelas 7 e 8, o Brasil, em mais de 95\%, foi o país que mais depositou pedido e teve patentes concedidas, no período. Para depósitos, Taiwan ficou classificado em segundo e Estados Unidos em terceiro. Já para concessão Estados Unidos ficou classificado em segundo e a Itália em terceiro lugar.

Confrontando os dados das Tabelas 7 e 8, apenas o Uruguai não se encontra classificado entre os dez países que tiveram mais concessões e o Japão não está presente entre os dez países que mais fizeram depósitos. Assim, com exceção desses dois países e considerando os demais, no total foram 59.473 depósitos e 7.850 concessões, o que representa que dos depósitos 13,2\% de patentes do tipo MU foram concedidas.

As Tabelas 9 e 10, representam os dez países com mais depósitos e os nove países que tiveram concessões de patentes do tipo de Certificado de Adição - CA, no período de 2000 a 2018, respectivamente. Conforme as Tabelas 9 e 10, o Brasil, aproximadamente em 90\%, foi o país que mais depositou e teve concessão de CA, seguido, em quantidades bem menores, dos Estados Unidos. Por esse motivo, considerando os dados do Brasil, o país possui 1.937 depósitos e 181 concessões, o que representa que dos depósitos 9,34\% de CA foram concedidas.

Além disso, apenas nove países tiveram CA concedidas, totalizando em 205 concessões. Percebe-se que apesar dos países Holanda, Suécia e África do Sul estarem entre os noves países, eles não compõem os países que mais depositaram.

A partir dos dados presentes nas tabelas referentes aos países que mais tiveram depósitos e concessões dos tipos PI, MU e CA, infere-se que há uma porcentagem relativamente pequena de concessões de patentes, visto que em média dos depósitos, $13 \%$ são concedidos. 
Research, Society and Development, v. 10, n. 4, e50210413791, 2021

(CC BY 4.0) | ISSN 2525-3409 | DOI: http://dx.doi.org/10.33448/rsd-v10i4.13791

Tabela 7: Dez países que tiveram mais depósitos do Tipo Modelo de Utilidade - MU, no período de 2000 a 2018, no Brasil.

\begin{tabular}{|c|c|c|c|c|c|c|c|c|c|c|c|}
\hline \multirow{2}{*}{ País } & \multirow{2}{*}{ Sigla do País } & \multicolumn{10}{|c|}{ Ano } \\
\hline & & 2000 & 2001 & 2002 & 2003 & $\ldots$ & 2015 & 2016 & 2017 & 2018 & Total por país \\
\hline Brasil & $\mathrm{BR}$ & 3200 & 3448 & 3478 & 3584 & $\cdots$ & 2607 & 2815 & 2843 & 2493 & 58336 \\
\hline Taiwan, Província da China & TW & 13 & 19 & 5 & 18 & $\cdots$ & 6 & 12 & 2 & 4 & 234 \\
\hline Estados Unidos & US & 12 & 9 & 5 & 9 & $\cdots$ & 28 & 24 & 13 & 11 & 223 \\
\hline China & $\mathrm{CN}$ & 11 & 3 & 10 & 5 & $\ldots$ & 15 & 18 & 14 & 21 & 174 \\
\hline Espanha & ES & 10 & 19 & 6 & 3 & $\ldots$ & 16 & 10 & 3 & 8 & 173 \\
\hline Argentina & AR & 19 & 19 & 9 & 1 & $\ldots$ & 2 & 5 & 2 & 6 & 117 \\
\hline Itália & IT & 9 & 5 & 5 & 1 & $\ldots$ & 4 & 11 & 7 & 3 & 107 \\
\hline Alemanha & $\mathrm{DE}$ & 4 & 3 & 7 & 5 & $\ldots$ & 5 & 6 & 6 & 2 & 66 \\
\hline França & $\mathrm{FR}$ & 1 & 3 & 1 & 0 & $\ldots$ & 2 & 13 & 3 & 0 & 43 \\
\hline Uruguai & UY & 1 & 3 & 5 & 2 & $\ldots$ & 0 & 1 & 3 & 3 & 37 \\
\hline Total por ano & & 3280 & 3531 & 3531 & 3628 & $\ldots$ & 2685 & 2915 & 2896 & 2551 & 59510 \\
\hline
\end{tabular}

Fonte: Adaptado de INPI (2020)

Tabela 8: Dez países que tiveram mais concessões do Tipo Modelo de Utilidade - MU, no período de 2000 a 2018, no Brasil.

\begin{tabular}{|c|c|c|c|c|c|c|c|c|c|c|c|}
\hline \multirow{2}{*}{ País } & \multirow{2}{*}{ Sigla do País } & \multicolumn{10}{|c|}{ Ano } \\
\hline & & 2000 & 2001 & 2002 & 2003 & $\ldots$ & 2015 & 2016 & 2017 & 2018 & Total por país \\
\hline Brasil & $B R$ & 402 & 312 & 338 & 444 & $\ldots$ & 466 & 550 & 764 & 1052 & 7621 \\
\hline Estados Unidos & us & 1 & 2 & 7 & 6 & $\ldots$ & 2 & 3 & 7 & 6 & 67 \\
\hline Itália & IT & 5 & 2 & 3 & 3 & $\ldots$ & 1 & 0 & 3 & 1 & 30 \\
\hline Alemanha & $\mathrm{DE}$ & 3 & 1 & 1 & 3 & $\ldots$ & 0 & 2 & 3 & 2 & 28 \\
\hline Espanha & ES & 0 & 3 & 1 & 3 & $\ldots$ & 2 & 0 & 1 & 1 & 26 \\
\hline Argentina & AR & 3 & 1 & 1 & 3 & $\ldots$ & 1 & 0 & 0 & 4 & 24 \\
\hline 」apão & $J P$ & 3 & 1 & 2 & 1 & $\ldots$ & 0 & 0 & 1 & 2 & 21 \\
\hline Taiwan, Província da China & TW & 0 & 0 & 0 & 0 & $\ldots$ & 0 & 0 & 0 & 3 & 21 \\
\hline França & $\mathrm{FR}$ & 2 & 1 & 2 & 0 & $\ldots$ & 2 & 0 & 0 & 2 & 19 \\
\hline China & $\mathrm{CN}$ & 2 & 0 & 0 & 2 & $\ldots$ & 2 & 3 & 0 & 2 & 14 \\
\hline Total por ano & & 421 & 323 & 355 & 465 & $\ldots$ & 476 & 558 & 779 & 1075 & 7871 \\
\hline
\end{tabular}

Fonte: Adaptado de INPI (2020). 
Tabela 9: Dez países que tiveram mais depósitos do Tipo Certificado de Adição - CA, no período de 2000 a 2018 , no Brasil.

\begin{tabular}{|c|c|c|c|c|c|c|c|c|c|c|c|}
\hline \multirow{2}{*}{ País } & \multirow{2}{*}{ Sigla do País } & \multicolumn{10}{|c|}{ Ano } \\
\hline & & 2000 & 2001 & 2002 & 2003 & $\ldots$ & 2015 & 2016 & 2017 & 2018 & Total por país \\
\hline Brasil & BR & 71 & 82 & 98 & 119 & $\ldots$ & 97 & 68 & 81 & 96 & 1937 \\
\hline Estados Unidos & us & 3 & 5 & 4 & 4 & $\ldots$ & 7 & 5 & 7 & 8 & 85 \\
\hline Reino Unido & GB & 0 & 0 & 0 & 0 & $\cdots$ & 0 & 0 & 1 & 0 & 8 \\
\hline França & FR & 0 & 0 & 0 & 1 & $\ldots$ & 0 & 0 & 0 & 0 & 7 \\
\hline Índia & IN & 1 & 1 & 0 & 0 & $\ldots$ & 0 & 0 & 1 & 0 & 7 \\
\hline Austrália & $\mathrm{AU}$ & 1 & 0 & 0 & 0 & $\ldots$ & 1 & 0 & 0 & 0 & 6 \\
\hline Alemanha & $\mathrm{DE}$ & 1 & 1 & 0 & 0 & $\ldots$ & 0 & 0 & 0 & 0 & 6 \\
\hline Canadá & CA & 0 & 0 & 0 & 1 & $\ldots$ & 0 & 0 & 0 & 0 & 5 \\
\hline Јapão & $J P$ & 0 & 0 & 0 & 1 & $\ldots$ & 0 & 0 & 0 & 0 & 5 \\
\hline Espanha & ES & 1 & 0 & 0 & 0 & $\ldots$ & 0 & 1 & 1 & 0 & 4 \\
\hline \multicolumn{2}{|c|}{ Total por ano } & 78 & 89 & 102 & 126 & $\ldots$ & 105 & 74 & 91 & 104 & 2070 \\
\hline
\end{tabular}

Fonte: Adaptado de INPI (2020).

Tabela 10: Nove países que tiveram concessões do Tipo Certificado de Adição - CA, no período de 2000 a 2018 , no Brasil.

\begin{tabular}{|c|c|c|c|c|c|c|c|c|c|c|c|}
\hline \multirow{2}{*}{ País } & \multirow{2}{*}{ Sigla do País } & \multicolumn{10}{|c|}{ Ano } \\
\hline & & 2000 & 2001 & 2002 & 2003 & $\ldots$ & 2015 & 2016 & 2017 & 2018 & Total por país \\
\hline Brasil & BR & 1 & 3 & 2 & 11 & $\ldots$ & 5 & 10 & 12 & 20 & 181 \\
\hline Estados Unidos & US & 0 & 0 & 0 & 1 & $\cdots$ & 0 & 1 & 0 & 3 & 12 \\
\hline Reino Unido & GB & 0 & 0 & 1 & 0 & $\ldots$ & 0 & 1 & 0 & 0 & 3 \\
\hline Јapão & $J P$ & 0 & 0 & 0 & 1 & $\cdots$ & 0 & 0 & 0 & 0 & 3 \\
\hline Canadá & CA & 0 & 0 & 0 & 0 & $\ldots$ & 0 & 0 & 0 & 0 & 2 \\
\hline Alemanha & $\mathrm{DE}$ & 0 & 0 & 0 & 0 & $\cdots$ & 0 & 0 & 0 & 1 & 1 \\
\hline Holanda & $N L$ & 0 & 0 & 0 & 0 & $\cdots$ & 0 & 0 & 0 & 0 & 1 \\
\hline Suécia & SE & 0 & 0 & 0 & 0 & $\cdots$ & 0 & 0 & 0 & 0 & 1 \\
\hline África do Sul & ZA & 0 & 0 & 0 & 0 & $\ldots$ & 0 & 0 & 0 & 0 & 1 \\
\hline \multicolumn{2}{|c|}{ Total por ano } & 1 & 3 & 3 & 13 & $\ldots$ & 5 & 12 & 12 & 24 & 205 \\
\hline
\end{tabular}

Fonte: Adaptado de INPI (2020). 


\subsubsection{Por tipo e natureza jurídica}

Em relação aos depósitos de patentes por depositante, classificados em pessoa física e pessoa jurídica, houve um aumento na participação dos pedidos de patentes de invenção por pessoas jurídicas, que desde 2012, vêm ultrapassando os de pessoas físicas e apresentando maior relevância. Na Tabela 11 pode-se observar essa mudança de perfil, considerando a evolução dos depositantes residentes no período de 2000 a 2018. Analisandose a Tabela 11, para as patentes do tipo MU, verifica-se que a quantidade de depósitos efetuados por pessoa física ainda predomina sobre a quantidade daqueles requeridos por pessoas jurídicas, mesmo nos anos mais recentes. Da mesma forma, seguem as patentes do tipo CA. No entanto, destaca-se que nos últimos anos avaliados (2017 e 2018) parece haver uma mudança de tendência, uma vez os dados estão se igualando. Verificase que em 2017, o INPI recebeu 41 CA por depositante residente pessoa física e 40 de pessoas jurídicas. Em 2018, esses números se igualam, sendo 48 CA de pessoas físicas e 48 jurídicas.

Considerando o total dos depósitos de cada tipo, pode-se inferir que os pedidos de patentes de depositantes residentes por pessoa física mantêm-se à frente, representando uma maior concentração naqueles recebidos pelo INPI dentro do período analisado, em que pese à exceção apresentada no último ano (2018), no qual o número de depósitos por pessoa jurídica (3.792) ultrapassou o de pessoas físicas (3.777). Isso mostra a necessidade da continuação desse para os próximos anos.

\subsubsection{Por tipo e via de entrada}

Considerando os depósitos de patentes por tipo e via de entrada, destaca-se que o MU é uma forma de proteção assim como a PI e da mesma maneira pode ser depositada no INPI via Sistema Internacional do PCT (INPI, 2020). Na Tabela 12 são apresentados os quantitativos dos depósitos por tipos de PI e MU, no período de análise de 2000 a 2018. 
Research, Society and Development, v. 10, n. 4, e50210413791, 2021

(CC BY 4.0) | ISSN 2525-3409 | DOI: http://dx.doi.org/10.33448/rsd-v10i4.13791

Tabela 11: Depósitos de Patentes por Tipo e Natureza Jurídica do Depositante Residente.

\begin{tabular}{|c|c|c|c|c|c|c|c|c|c|c|}
\hline \multirow{3}{*}{ Ano } & \multicolumn{9}{|c|}{ Tipo } & \multirow{3}{*}{ Total } \\
\hline & \multicolumn{2}{|c|}{ PI } & \multicolumn{2}{|c|}{ MU } & \multicolumn{2}{|c|}{ CA } & \multicolumn{3}{|c|}{ Total } & \\
\hline & PF & PJ & PF & PJ & PF & PJ & PF & PJ & N.A. ${ }^{(1)}$ & \\
\hline 2001 & 2465 & 974 & 2697 & 751 & 55 & 27 & 5217 & 1752 & 0 & 6969 \\
\hline 2002 & 2336 & 1139 & 2653 & 824 & 76 & 22 & 5065 & 1985 & 2 & 7052 \\
\hline 2003 & 2540 & 1321 & 2673 & 911 & 93 & 26 & 5306 & 2258 & 0 & 7564 \\
\hline 2005 & 2535 & 1512 & 2442 & 740 & 86 & 31 & 5063 & 2283 & 0 & 7346 \\
\hline 2006 & 2462 & 1495 & 2458 & 667 & 66 & 46 & 4986 & 2208 & 0 & 7194 \\
\hline 2007 & 2600 & 1593 & 2330 & 676 & 89 & 37 & 5019 & 2306 & 1 & 7326 \\
\hline 2008 & 2588 & 1679 & 2546 & 781 & 87 & 29 & 5221 & 2489 & 1 & 7711 \\
\hline 2009 & 2505 & 1757 & 2466 & 866 & 67 & 48 & 5038 & 2671 & 0 & 7709 \\
\hline 2013 & 2450 & 2505 & 2091 & 801 & 73 & 51 & 4614 & 3357 & 0 & 7971 \\
\hline 2014 & 2102 & 2555 & 1857 & 782 & 62 & 36 & 4021 & 3373 & 0 & 7394 \\
\hline 2015 & 2148 & 2492 & 1830 & 777 & 56 & 41 & 4034 & 3310 & 0 & 7344 \\
\hline 2016 & 2586 & 2613 & 1948 & 867 & 43 & 25 & 4577 & 3505 & 0 & 8082 \\
\hline 2017 & 2575 & 2905 & 1920 & 923 & 41 & 40 & 4536 & 3868 & 0 & 8404 \\
\hline 2018 & 2081 & 2899 & 1648 & 845 & 48 & 48 & 3777 & 3792 & 0 & 7569 \\
\hline
\end{tabular}

Nota: N.A.: Não avaliados por não identificação da natureza jurídica do $1^{\circ}$ depositante residente.

Fonte: INPI (2020). 
Research, Society and Development, v. 10, n. 4, e50210413791, 2021

(CC BY 4.0) | ISSN 2525-3409 | DOI: http://dx.doi.org/10.33448/rsd-v10i4.13791

Tabela 12: Depósitos de Patentes por Tipo e Via de entrada.

\begin{tabular}{l|rrrrrrrr}
\hline \multirow{2}{*}{ Ano } & \multicolumn{2}{|c|}{ Patente de Invenção } & \multicolumn{3}{c|}{ Modelo de Utilidade } \\
\cline { 2 - 7 } & Via Direta & Via PCT & Total & Via Direta & Via PCT & Total \\
\hline 2000 & 6848 & 10596 & 17444 & 3321 & 11 & 3332 \\
2001 & 6720 & 11187 & 17907 & 3552 & 6 & 3558 \\
2002 & 5933 & 10752 & 16685 & 3537 & 9 & 3546 \\
2003 & 6031 & 10379 & 16410 & 3632 & 8 & 3640 \\
2004 & 6397 & 10310 & 16707 & 3593 & 9 & 3602 \\
2005 & 6469 & 12017 & 18486 & 3236 & 7 & 3243 \\
2006 & 6187 & 13664 & 19851 & 3177 & 4 & 3181 \\
2007 & 6388 & 15268 & 21656 & 3042 & 2 & 3044 \\
2008 & 6290 & 16830 & 23120 & 3385 & 7 & 3392 \\
2009 & 6224 & 16159 & 22383 & 3366 & 12 & 3378 \\
2010 & 6283 & 18703 & 24986 & 2990 & 15 & 3005 \\
2011 & 7317 & 21341 & 28658 & 3104 & 30 & 3134 \\
2012 & 7760 & 22675 & 30435 & 2980 & 30 & 3010 \\
2013 & 7931 & 22946 & 30877 & 2969 & 66 & 3035 \\
2014 & 7356 & 22985 & 30341 & 2686 & 48 & 2734 \\
2015 & 7311 & 22906 & 30217 & 2652 & 67 & 2719 \\
2016 & 7809 & 20200 & 28009 & 2864 & 73 & 2937 \\
2017 & 7390 & 18268 & 25658 & 2869 & 49 & 2918 \\
2018 & 6842 & 18015 & 24857 & 2539 & 48 & 2587 \\
\hline
\end{tabular}

Fonte: INPI (2020).

No tocante ao comportamento dos depósitos, o instituto demonstra a sua evolução nos anos de referência:

Analisando todo o período 2008-2018, cabe assinalar que os pedidos via PCT, após a queda ocorrida em 2009, experimentaram taxas seguidas de crescimento, até 2014, quando foi alcançado o máximo de 22.985 pedidos depositados. No entanto, a partir de 2015, ocorrerem quedas contínuas, inclusive no ano de 2018, que seguiu o mesmo comportamento de declínio. Os depósitos feitos diretamente no INPI, que em 2013 chegaram ao número máximo de 7.931, vêm sofrendo oscilações e, em 2018, recuaram a níveis pouco acima do triênio 2008-2010, os menores resultados da série (INPI, 2020, p. 11).

O número de pedidos de modelos de utilidade alcançou 2.587 em 2018, o que representou um decréscimo de $11,3 \%$ em relação ao ano anterior. Os depósitos de modelos de utilidade vêm perdendo relevância desde o ano de 2008 , quando alcançaram 3.392 depósitos. Com esta retração, observa-se que os depósitos de pedidos de modelos de utilidade em 2018 foram inferiores aos observados em 2014 e 2015, considerados os menores do período 2008-2017 (INPI, 2020, p. 17).

Comparando os dois tipos no período em análise, vislumbra-se que os números totais de depósitos apresentam comportamento inverso quando considerados por via de entrada. Ao analisar-se a Tabela 12, percebe-se que nos depósitos via PCT as PI destacam-se em maior número, enquanto os depósitos por MU apresentam números maiores pela entrada direta no INPI.

\subsubsection{Pelo campo tecnológico}

Nas Tabelas 13 e 14 estão representados, respectivamente, os Depósitos e as Concessões de Patentes de Invenção correspondentes à $1^{\mathrm{a}}$ Classe da Classificação Internacional de Patente (International Patent Classification -IPC). A IPC ocorre 
Research, Society and Development, v. 10, n. 4, e50210413791, 2021

(CC BY 4.0) | ISSN 2525-3409 | DOI: http://dx.doi.org/10.33448/rsd-v10i4.13791

de maneira hierárquica com a adição dos detalhes de invenção em diferentes níveis. Através de tal sistema é possível a avaliação da novidade e atividade inventiva dos pedidos de patentes, além da compreensão, a cada área tecnológica dos depósitos. Com a metodologia da WIPO, foi realizado o mapeamento do depósito de patentes de acordo com os campos tecnológicos (INPI, 2020).

As Tabelas 13 e 14 apresentaram, respectivamente, um aumento de 42,50\% nos depósitos e de 59,03\% nas concessões de PI no período de 2000 a 2018. Nos últimos cinco anos é possível observar, na Tabela 13 a presença de um padrão de Química Orgânica Fina, Produtos Farmacêuticos, Tecnologia Médica, Química de Materiais Básicos e Biotecnologia como as tecnologias que mais apresentam depósitos. No ano de 2018, essas mesmas áreas representaram um percentual de 29,78\% dos pedidos.

Observa-se na Tabela 14 que no ano de 2018 as tecnologias de PI com maior número de concessões foram Química Orgânica Fina, Química de Materiais Básicos, Outras Máquinas Especiais, Tecnologia Médica e Engenharia Civil, representando um percentual de 35,29\%. Outro dado importante é a elevação de 82,90\% de concessões em relação a 2017 , que é apontado como resultado de novos procedimentos pelo INPI visando a otimização do processo de exame das patentes à sua disposição (INPI, 2020). 
Research, Society and Development, v. 10, n. 4, e50210413791, 2021

(CC BY 4.0) | ISSN 2525-3409 | DOI: http://dx.doi.org/10.33448/rsd-v10i4.13791

Tabela 13: Depósitos de Patentes do Tipo Patente de Invenção pelo Campo Tecnológico correspondente à 1a. Classe IPC.

\begin{tabular}{|c|c|c|c|c|c|c|c|c|c|c|c|}
\hline \multirow{2}{*}{ Setor } & \multirow{2}{*}{ Área } & \multirow{2}{*}{ Campo } & \multicolumn{9}{|c|}{ Ano } \\
\hline & & & 2000 & 2001 & 2002 & $\ldots$ & 2014 & 2015 & 2016 & 2017 & 2018 \\
\hline & Aparatos eletrônicos, Engenharia eletrônica e Energia elétrica & 1 & 713 & 701 & 634 & $\ldots$ & 1270 & 1138 & 971 & 774 & 771 \\
\hline & Tecnologia Audiovisual & 2 & 403 & 400 & 339 & ... & 544 & 382 & 239 & 143 & 160 \\
\hline & Telecomunicações & 3 & 957 & 776 & 582 & $\ldots$ & 327 & 285 & 319 & 321 & 228 \\
\hline Eng enharia Elétrica & Comunicação Digital & 4 & 234 & 231 & 210 & $\ldots$ & 893 & 942 & 1424 & 1187 & 1129 \\
\hline \multirow[t]{6}{*}{ e Eletrônica } & Processos básicos de comunicação & 5 & 102 & 85 & 51 & $\ldots$ & 58 & 62 & 88 & 55 & 55 \\
\hline & Informática & 6 & 411 & 452 & 441 & ... & 1083 & 1183 & 1108 & 734 & 620 \\
\hline & Métodos de Tecnologia da Informação para gestão & 7 & 13 & 15 & 15 & $\ldots$ & 272 & 293 & 271 & 290 & 243 \\
\hline & Semicondutores & 8 & 26 & 34 & 35 & $\ldots$ & 105 & 120 & 108 & 88 & 81 \\
\hline & Ótica & 9 & 226 & 225 & 186 & $\ldots$ & 365 & 312 & 256 & 219 & 183 \\
\hline & Medidas & 10 & 392 & 430 & 342 & $\ldots$ & 1087 & 1044 & 863 & 742 & 658 \\
\hline \multirow[t]{8}{*}{ Instrumentos } & Análise de materiais Biológicos & 11 & 61 & 92 & 54 & $\ldots$ & 203 & 199 & 151 & 147 & 131 \\
\hline & Controle & 12 & 285 & 275 & 267 & ... & 391 & 410 & 336 & 333 & 259 \\
\hline & Tecnologia Médica & 13 & 794 & 825 & 824 & $\ldots$ & 1948 & 1990 & 1633 & 1582 & 1625 \\
\hline & Quimica Orgânica Fina & 14 & 1358 & 1441 & 1498 & $\ldots$ & 2015 & 2075 & 1834 & 1738 & 1620 \\
\hline & Biotecnologia & 15 & 672 & 646 & 587 & $\ldots$ & 1486 & 1433 & 1261 & 1366 & 1280 \\
\hline & Produtos Farmacêuticos & 16 & 896 & 994 & 982 & $\ldots$ & 1573 & 1711 & 1505 & 1619 & 1651 \\
\hline & Química Macromolecular, polimeros & 17 & 754 & 715 & 722 & $\ldots$ & 998 & 857 & 768 & 732 & 634 \\
\hline & Quimica de al imentos & 18 & 343 & 319 & 329 & $\ldots$ & 707 & 735 & 646 & 638 & 758 \\
\hline \multirow[t]{9}{*}{ Quimica } & Química de materiais básicos & 19 & 829 & 924 & 899 & $\ldots$ & 1552 & 1542 & 1373 & 1376 & 1227 \\
\hline & Materiais, Metalurgia & 20 & 494 & 509 & 454 & $\ldots$ & 770 & 739 & 718 & 747 & 654 \\
\hline & Tecnologia de superfícies, revestimentos & 21 & 267 & 345 & 307 & $\ldots$ & 494 & 460 & 438 & 380 & 384 \\
\hline & Tecnologia de microestruturas, nanotecnologia & 22 & 1 & 2 & 2 & $\ldots$ & 13 & 7 & 14 & 5 & 1 \\
\hline & Engenharia química & 23 & 515 & 520 & 530 & $\ldots$ & 977 & 893 & 780 & 699 & 607 \\
\hline & Tecnologias de Meio Ambiente & 24 & 223 & 216 & 205 & $\ldots$ & 484 & 419 & 383 & 376 & 320 \\
\hline & Manejo & 25 & 695 & 776 & 709 & $\ldots$ & 939 & 927 & 919 & 850 & 668 \\
\hline & Máquinas ferramentas & 26 & 400 & 399 & 344 & $\ldots$ & 703 & 679 & 556 & 502 & 378 \\
\hline & Motores, Bombas, Turbinas & 27 & 479 & 544 & 442 & $\ldots$ & 965 & 1054 & 982 & 680 & 486 \\
\hline \multirow{6}{*}{$\begin{array}{l}\text { Engenharia } \\
\text { mecânica }\end{array}$} & Máquinas Têxteis e de papel & 28 & 495 & 486 & 419 & $\ldots$ & 491 & 482 & 413 & 415 & 368 \\
\hline & Outras máquinas especiais & 29 & 739 & 745 & 756 & $\ldots$ & 1205 & 1279 & 1280 & 1122 & 1115 \\
\hline & Processos Térmicos e aparatos & 30 & 199 & 331 & 195 & $\ldots$ & 365 & 332 & 275 & 230 & 190 \\
\hline & Elementos mecânicos & 31 & 658 & 666 & 617 & $\ldots$ & 903 & 906 & 789 & 687 & 581 \\
\hline & Transporte & 32 & 904 & 906 & 842 & $\ldots$ & 1531 & 1656 & 1424 & 1230 & 914 \\
\hline & Móveis, jog os & 33 & 374 & 335 & 411 & $\ldots$ & 478 & 483 & 415 & 371 & 298 \\
\hline \multirow[t]{2}{*}{ Outros setores } & Outros bens de consumo & 34 & 425 & 433 & 374 & $\ldots$ & 621 & 583 & 535 & 419 & 411 \\
\hline & Engenharia Civil & 35 & 617 & 665 & 647 & $\ldots$ & 1353 & 1362 & 1262 & 1189 & 770 \\
\hline & & N.A. ${ }^{(1)}$ & 490 & 449 & 434 & $\ldots$ & 1172 & 1243 & 1672 & 1672 & 3399 \\
\hline
\end{tabular}

Legenda: (1) Os depósitos de patentes foram tabelados considerando o campo tecnológico correspondente ao primeiro símbolo de classificação dos pedidos já publicados na data da extração dos dados. N.A.: Não avaliados por não possuírem classificação ou campo tecnológico correspondente.

Fonte: Adaptado de INPI, (2020). 
Research, Society and Development, v. 10, n. 4, e50210413791, 2021

(CC BY 4.0) | ISSN 2525-3409 | DOI: http://dx.doi.org/10.33448/rsd-v10i4.13791

Tabela 14: Concessões de Patentes do Tipo Patente de Invenção pelo Campo Tecnológico correspondente à 1a. Classe IPC.

\begin{tabular}{|c|c|c|c|c|c|c|c|c|c|c|}
\hline \multirow{2}{*}{ Setor } & \multirow{2}{*}{ Área } & \multirow{2}{*}{ Campo } & \multicolumn{8}{|c|}{ Ano } \\
\hline & & & 2000 & 2001 & $\ldots$ & 2014 & 2015 & 2016 & 2017 & 2018 \\
\hline \multirow{8}{*}{$\begin{array}{c}\text { Engenharia Elétrica e } \\
\text { Eletrônica }\end{array}$} & Aparatos eletrônicos, Eng enharia eletrônica e Energia elétric & 1 & 308 & 158 & $\ldots$ & 52 & 103 & 160 & 211 & 339 \\
\hline & Tecnologia Audiovisual & 2 & 86 & 44 & $\ldots$ & 32 & 62 & 83 & 74 & 130 \\
\hline & Telecomunicações & 3 & 107 & 34 & $\ldots$ & 63 & 106 & 149 & 138 & 197 \\
\hline & Comunicação Digital & 4 & 23 & 9 & $\ldots$ & 31 & 57 & 82 & 123 & 166 \\
\hline & Processos básicos de comunicação & 5 & 23 & 7 & $\ldots$ & 9 & 13 & 9 & 10 & 15 \\
\hline & Informática & 6 & 47 & 25 & $\ldots$ & 23 & 52 & 75 & 128 & 176 \\
\hline & Métodos de Tecnologia da Informação para gestão & 7 & 0 & 0 & $\ldots$ & 0 & 0 & 0 & 5 & 1 \\
\hline & Semicondutores & 8 & 2 & 3 & $\ldots$ & 2 & 4 & 12 & 13 & 33 \\
\hline \multirow{5}{*}{ Instrumentos } & Ótica & 9 & 78 & 21 & $\ldots$ & 18 & 26 & 25 & 62 & 144 \\
\hline & Medidas & 10 & 96 & 28 & $\ldots$ & 67 & 63 & 100 & 299 & 361 \\
\hline & Análise de materiais Biológicos & 11 & 4 & 8 & $\ldots$ & 5 & 10 & 35 & 26 & 51 \\
\hline & Controle & 12 & 48 & 18 & $\ldots$ & 15 & 28 & 36 & 56 & 79 \\
\hline & Tecnologia Médica & 13 & 189 & 232 & $\ldots$ & 136 & 182 & 169 & 189 & 641 \\
\hline \multirow{11}{*}{ Quimica } & Quimica Orgânica Fina & 14 & 526 & 138 & $\ldots$ & 252 & 346 & 539 & 637 & 902 \\
\hline & Biotecnologia & 15 & 102 & 26 & $\ldots$ & 96 & 132 & 185 & 226 & 348 \\
\hline & Produtos Farmacêuticos & 16 & 52 & 16 & $\ldots$ & 67 & 112 & 143 & 128 & 279 \\
\hline & Química Macromolecular, polímeros & 17 & 392 & 181 & $\ldots$ & 108 & 90 & 136 & 164 & 347 \\
\hline & Química de alimentos & 18 & 42 & 14 & $\ldots$ & 128 & 146 & 137 & 175 & 320 \\
\hline & Química de materiais básicos & 19 & 486 & 235 & $\ldots$ & 307 & 333 & 484 & 544 & 758 \\
\hline & Materiais, Metalurgia & 20 & 447 & 175 & $\ldots$ & 207 & 191 & 198 & 307 & 484 \\
\hline & Tecnologia de superficies, revestimentos & 21 & 172 & 85 & $\ldots$ & 63 & 75 & 88 & 79 & 175 \\
\hline & Tecnologia de microestruturas, nanotecnologia & 22 & 0 & 0 & $\ldots$ & 1 & 1 & 2 & 0 & 4 \\
\hline & Engenharia quimica & 23 & 261 & 154 & $\ldots$ & 128 & 145 & 189 & 236 & 435 \\
\hline & Tecnologias de Meio Ambiente & 24 & 113 & 76 & $\ldots$ & 37 & 45 & 59 & 57 & 139 \\
\hline \multirow{8}{*}{ Engenharia mecânica } & Manejo & 25 & 393 & 221 & $\ldots$ & 91 & 84 & 92 & 137 & 496 \\
\hline & Máquinas ferramentas & 26 & 287 & 104 & $\ldots$ & 83 & 87 & 42 & 102 & 192 \\
\hline & Motores, Bombas, Turbinas & 27 & 162 & 122 & $\ldots$ & 46 & 39 & 32 & 61 & 209 \\
\hline & Máquinas Têxteis e de papel & 28 & 316 & 189 & $\ldots$ & 96 & 127 & 161 & 181 & 248 \\
\hline & Outras máquinas especiais & 29 & 289 & 168 & $\ldots$ & 183 & 175 & 223 & 302 & 670 \\
\hline & Processos Térmicos e aparatos & 30 & 142 & 80 & $\ldots$ & 23 & 34 & 10 & 55 & 94 \\
\hline & Elementos mecânicos & 31 & 368 & 184 & $\ldots$ & 78 & 105 & 117 & 110 & 339 \\
\hline & Transporte & 32 & 294 & 206 & $\ldots$ & 66 & 108 & 99 & 137 & 386 \\
\hline \multirow{3}{*}{ Outros setores } & Móveis, jogos & 33 & 33 & 70 & $\ldots$ & 30 & 35 & 36 & 70 & 78 \\
\hline & Outros bens de consumo & 34 & 96 & 130 & $\ldots$ & 35 & 49 & 54 & 131 & 156 \\
\hline & Engenharia Civil & 35 & 162 & 114 & $\ldots$ & 110 & 173 & 210 & 260 & 547 \\
\hline & & N.A..$^{(1)}$ & 122 & 23 & $\ldots$ & 63 & 73 & 24 & 17 & 29 \\
\hline & & Total & 6268 & 3298 & $\ldots$ & 2751 & 3411 & 4195 & 5450 & 9968 \\
\hline
\end{tabular}

Legenda: (1) As concessões de patentes foram tabeladas considerando o campo tecnológico correspondente ao primeiro símbolo de classificação dos pedidos. N.A.: Não avaliados por não possuírem campo tecnológico correspondente ao símbolo de classificação Fonte: Adaptado de INPI, (2020). 
Nas Tabelas 15 e 16 estão representados, respectivamente, os Depósitos e as Concessões de MU correspondentes à $1^{\mathrm{a}}$ Classe da IPC. Elas apresentaram, respectivamente, um decréscimo de $22,36 \%$ nos depósitos e um aumento de 157,75\% nas concessões de modelo de utilidade no período de 2000 a 2018.

Nos últimos três anos é possível observar, na Tabela 15 a presença de um padrão de Móveis, Jogos, Engenharia Civil, Outras Máquinas Especiais, Manejo e Outros Bens de Consumo como as maiores responsáveis por depósitos de patentes de MU. No ano de 2018, tais tecnologias representaram 27,25\% do total desses pedidos.

Pela Tabela 16, verifica-se que no ano de 2018 as tecnologias de PI com maior número de concessões foram: Outras máquinas especiais, Engenharia Civil, Móveis, jogos, Manejo, Tecnologia Médica e Transporte, representando um percentual de 60,84\%. Aponta-se ainda para o aumento de 39,34\% de concessões em relação a 2017, com destaque para a informação da menor complexidade na concessão para MU quando comparada a PI (INPI, 2020).

\subsection{Análise dos dados da WIPO}

Os dados estatísticos de patentes foram extraídos do banco de dados de estatísticas da OMPI (Organização Mundial de Propriedade Intelectual). Dentro do banco de dados da WIPO há diversas informações na forma de indicadores que mensuram a quantidade de patentes registradas, patentes em vigor, por área da tecnologia e muitos outros tipos de indicadores, de acordo com os escritórios de todo mundo, podendo selecionar o período desejado desde 1980 a 2018. Dentro do centro de dados há as categorias: indicadores-chave, patentes, marca, design industrial, modelo utilitário, indicações geográficas, PCT, Madrid, Haia e pesquisas salvas. Para o presente trabalho foram analisados os resultados do indicador-chave "Modelo de utilidade - Aplicações para os 10 maiores escritórios". Tal indicador apresenta dados dos 10 maiores escritórios do mundo do período e 2004 a 2018.

A Tabela 17 apresenta o número de patentes aplicadas nos escritórios do Brasil, China, Alemanha, Japão, República da Coreia, Rússia, Espanha, Tailândia, Turquia e Ucrânia entre os anos de 2004 a 2018. Com base na Tabela 17 o Brasil está entre os 10 maiores escritórios de aplicações de MU. Entretanto, a China é o que mais possui aplicações durante o período de 2004 a 2018. 
Tabela 15: Depósitos de Patentes do Tipo Modelo de Utilidade pelo Campo Tecnológico correspondente à $1^{\text {a }}$. Classe IPC.

\begin{tabular}{|c|c|c|c|c|c|c|c|c|c|c|}
\hline \multirow{2}{*}{ Setor } & \multirow{2}{*}{ Área } & \multirow{2}{*}{ Campo } & \multicolumn{8}{|c|}{ Ano } \\
\hline & & & 2000 & 2001 & $\ldots$ & 2014 & 2015 & 2016 & 2017 & 2018 \\
\hline & Aparatos eletrônicos, Engenharia eletrônica e Energia elétrica & 1 & 147 & 167 & $\ldots$ & 76 & 69 & 95 & 86 & 54 \\
\hline & Tecnologia Audiovisual & 2 & 130 & 101 & $\ldots$ & 35 & 19 & 24 & 25 & 16 \\
\hline & Telecomunicações & 3 & 41 & 45 & $\ldots$ & 7 & 15 & 13 & 12 & 6 \\
\hline Engenharia Elétrica e & Comunicação Digital & 4 & 1 & 5 & $\ldots$ & 3 & 3 & 5 & 3 & 4 \\
\hline \multirow[t]{6}{*}{ Eletrônica } & Processos básicos de comunicação & 5 & 3 & 3 & $\ldots$ & 1 & 0 & 2 & 1 & 2 \\
\hline & Informática & 6 & 32 & 16 & $\ldots$ & 7 & 5 & 11 & 15 & 8 \\
\hline & Métodos de Tecnologia da Informação para gestão & 7 & 2 & 0 & $\ldots$ & 4 & 7 & 9 & 2 & 2 \\
\hline & Semicondutores & 8 & 2 & 0 & $\ldots$ & 1 & 0 & 5 & 0 & 1 \\
\hline & Ótica & 9 & 23 & 22 & $\ldots$ & 7 & 12 & 19 & 24 & 8 \\
\hline & Medidas & 10 & 51 & 66 & $\ldots$ & 22 & 29 & 33 & 34 & 16 \\
\hline \multirow[t]{8}{*}{ Instrumentos } & Análise de materiais Biológicos & 11 & 3 & 1 & $\ldots$ & 0 & 3 & 0 & 0 & 1 \\
\hline & Controle & 12 & 74 & 57 & $\ldots$ & 42 & 43 & 36 & 42 & 24 \\
\hline & Tecnologia Médica & 13 & 148 & 161 & $\ldots$ & 109 & 141 & 162 & 156 & 101 \\
\hline & Quimica Orgânica Fina & 14 & 0 & 0 & $\ldots$ & 2 & 1 & 1 & 2 & 0 \\
\hline & Biotecnologia & 15 & 1 & 0 & $\ldots$ & 1 & 0 & 2 & 3 & 0 \\
\hline & Produtos Farmacêuticos & 16 & 2 & 2 & $\ldots$ & 2 & 1 & 4 & 2 & 1 \\
\hline & Química Macromolecular, polímeros & 17 & 1 & 2 & $\ldots$ & 0 & 0 & 1 & 0 & 0 \\
\hline & Química de alimentos & 18 & 12 & 16 & $\ldots$ & 8 & 12 & 15 & 20 & 12 \\
\hline \multirow[t]{9}{*}{ Quimica } & Química de materiais básicos & 19 & 11 & 10 & $\ldots$ & 4 & 6 & 6 & 13 & 7 \\
\hline & Materiais, Metalurgia & 20 & 6 & 6 & $\ldots$ & 6 & 2 & 3 & 12 & 3 \\
\hline & Tecnologia de superfícies, revestimentos & 21 & 6 & 17 & $\ldots$ & 11 & 11 & 10 & 14 & 3 \\
\hline & Tecnologia de microestruturas, nanotecnologia & 22 & 0 & 0 & $\ldots$ & 0 & 0 & 0 & 0 & 0 \\
\hline & Engenharia química & 23 & 49 & 72 & $\ldots$ & 50 & 64 & 50 & 43 & 36 \\
\hline & Tecnologias de Meio Ambiente & 24 & 43 & 49 & $\ldots$ & 38 & 39 & 34 & 45 & 26 \\
\hline & Manejo & 25 & 350 & 358 & $\ldots$ & 200 & 171 & 233 & 186 & 133 \\
\hline & Máquinas ferramentas & 26 & 100 & 89 & $\ldots$ & 70 & 49 & 69 & 48 & 34 \\
\hline & Motores, Bombas, Turbinas & 27 & 32 & 66 & $\ldots$ & 26 & 35 & 36 & 32 & 19 \\
\hline \multirow{6}{*}{$\begin{array}{l}\text { Engenharia } \\
\text { mecânica }\end{array}$} & Máquinas Têxteis e de papel & 28 & 53 & 59 & $\ldots$ & 14 & 15 & 27 & 19 & 9 \\
\hline & Outras máquinas especiais & 29 & 235 & 260 & $\ldots$ & 217 & 215 & 255 & 258 & 141 \\
\hline & Processos Térmicos e aparatos & 30 & 52 & 125 & $\ldots$ & 45 & 55 & 35 & 51 & 17 \\
\hline & Elementos mecânicos & 31 & 121 & 141 & $\ldots$ & 79 & 57 & 69 & 65 & 34 \\
\hline & Transporte & 32 & 290 & 277 & $\ldots$ & 178 & 181 & 177 & 162 & 100 \\
\hline & Móveis, jog os & 33 & 554 & 523 & $\ldots$ & 257 & 282 & 307 & 284 & 167 \\
\hline \multirow[t]{4}{*}{ Outros setores } & Outros bens de consumo & 34 & 299 & 376 & $\ldots$ & 138 & 160 & 202 & 167 & 106 \\
\hline & Eng enharia Civil & 35 & 363 & 332 & $\ldots$ & 260 & 269 & 267 & 263 & 158 \\
\hline & & N.A. ${ }^{(1)}$ & 95 & 134 & $\ldots$ & 814 & 748 & 720 & 829 & 1338 \\
\hline & & Total & 3332 & 3558 & . & 2734 & 2719 & 2937 & 2918 & 2587 \\
\hline
\end{tabular}

Legenda: (1) Os depósitos de patentes foram tabelados considerando o campo tecnológico correspondente ao primeiro símbolo de classificação dos pedidos já publicados na data da extração dos dados. N.A.: Não avaliados por não possuírem classificação ou campo tecnológico correspondente. Fonte: Adaptado de INPI, (2020). 
Tabela 16: Concessões de Patentes do Tipo Modelo de Utilidade pelo Campo Tecnológico correspondente à 1a. Classe IPC.

\begin{tabular}{|c|c|c|c|c|c|c|c|c|c|c|}
\hline \multirow{2}{*}{ Setor } & \multirow{2}{*}{ Área } & \multirow{2}{*}{ Campo } & \multicolumn{8}{|c|}{ Ano } \\
\hline & & & 2000 & 2001 & $\ldots$ & 2014 & 2015 & 2016 & 2017 & 2018 \\
\hline & Aparatos eletrônicos, Eng enharia eletrônica e Energia elétrica & 1 & 37 & 32 & $\ldots$ & 26 & 42 & 32 & 48 & 61 \\
\hline & Tecnologia Audiovisual & 2 & 15 & 6 & $\ldots$ & 10 & 6 & 8 & 14 & 6 \\
\hline & Telecomunicações & 3 & 6 & 2 & $\ldots$ & 4 & 4 & 2 & 6 & 5 \\
\hline Engenharia Elétrica & Comunicação Digital & 4 & 0 & 0 & $\ldots$ & 0 & 0 & 0 & 1 & 0 \\
\hline \multirow[t]{6}{*}{ e Eletrônica } & Processos básicos de comunicação & 5 & 0 & 0 & $\ldots$ & 0 & 0 & 0 & 0 & 0 \\
\hline & Informática & 6 & 0 & 1 & $\ldots$ & 2 & 5 & 3 & 1 & 4 \\
\hline & Métodos de Tecnologia da Informação para gestão & 7 & 0 & 0 & $\ldots$ & 0 & 0 & 1 & 0 & 1 \\
\hline & Semicondutores & 8 & 0 & 0 & $\ldots$ & 0 & 0 & 0 & 1 & 0 \\
\hline & Ótica & 9 & 7 & 1 & $\ldots$ & 1 & 1 & 0 & 4 & 6 \\
\hline & Medidas & 10 & 9 & 1 & $\ldots$ & 11 & 8 & 12 & 11 & 18 \\
\hline \multirow[t]{8}{*}{ Instrumentos } & Análise de materiais Biológicos & 11 & 1 & 0 & $\ldots$ & 1 & 0 & 1 & 0 & 2 \\
\hline & Controle & 12 & 6 & 2 & $\ldots$ & 4 & 4 & 8 & 12 & 15 \\
\hline & Tecnologia Médica & 13 & 15 & 21 & $\ldots$ & 19 & 32 & 35 & 60 & 97 \\
\hline & Química Orgânica Fina & 14 & 0 & 0 & $\ldots$ & 0 & 0 & 0 & 1 & 0 \\
\hline & Biotecnologia & 15 & 0 & 0 & $\ldots$ & 0 & 0 & 1 & 1 & 1 \\
\hline & Produtos Farmacêuticos & 16 & 0 & 0 & $\ldots$ & 0 & 0 & 0 & 1 & 1 \\
\hline & Química Macromolecular, polímeros & 17 & 0 & 0 & $\ldots$ & 0 & 0 & 0 & 0 & 0 \\
\hline & Química de alimentos & 18 & 1 & 1 & $\ldots$ & 3 & 2 & 1 & 2 & 1 \\
\hline \multirow[t]{9}{*}{ Quimica } & Química de materiais básicos & 19 & 1 & 1 & $\ldots$ & 0 & 2 & 1 & 1 & 3 \\
\hline & Materiais, Metalurgia & 20 & 0 & 0 & $\ldots$ & 0 & 1 & 2 & 5 & 4 \\
\hline & Tecnologia de superfícies, revestimentos & 21 & 1 & 2 & $\ldots$ & 0 & 2 & 8 & 4 & 9 \\
\hline & Tecnologia de microestruturas, nanotecnologia & 22 & 0 & 0 & $\ldots$ & 0 & 0 & 0 & 0 & 0 \\
\hline & Engenharia química & 23 & 6 & 11 & $\ldots$ & 10 & 8 & 16 & 28 & 45 \\
\hline & Tecnologias de Meio Ambiente & 24 & 3 & 2 & $\ldots$ & 6 & 6 & 14 & 13 & 23 \\
\hline & Manejo & 25 & 100 & 57 & $\ldots$ & 40 & 68 & 61 & 90 & 101 \\
\hline & Máquinas ferramentas & 26 & 16 & 11 & $\ldots$ & 18 & 17 & 8 & 17 & 37 \\
\hline & Motores, Bombas, Turbinas & 27 & 14 & 5 & $\ldots$ & 7 & 6 & 12 & 13 & 11 \\
\hline \multirow{5}{*}{$\begin{array}{c}\text { Engenharia } \\
\text { mecânica }\end{array}$} & Máquinas Têxteis e de papel & 28 & 3 & 4 & $\ldots$ & 2 & 5 & 8 & 8 & 14 \\
\hline & Outras máquinas especiais & 29 & 18 & 26 & $\ldots$ & 31 & 33 & 65 & 67 & 129 \\
\hline & Processos Térmicos e aparatos & 30 & 9 & 13 & $\ldots$ & 10 & 22 & 19 & 15 & 32 \\
\hline & Elementos mecânicos & 31 & 28 & 26 & $\ldots$ & 34 & 42 & 30 & 42 & 52 \\
\hline & Transporte & 32 & 40 & 27 & $\ldots$ & 21 & 29 & 35 & 83 & 97 \\
\hline \multirow{5}{*}{ Outros setores } & Móveis, jogos & 33 & 30 & 29 & $\ldots$ & 35 & 51 & 55 & 80 & 121 \\
\hline & Outros bens de consumo & 34 & 23 & 18 & $\ldots$ & 15 & 15 & 41 & 69 & 72 \\
\hline & Engenharia Civil & 35 & 37 & 26 & $\ldots$ & 55 & 67 & 85 & 89 & 123 \\
\hline & & N.A. ${ }^{(1)}$ & 0 & 1 & $\ldots$ & 1 & 1 & 0 & 1 & 7 \\
\hline & & Total & 426 & 326 & $\ldots$ & 366 & 479 & 564 & 788 & 1098 \\
\hline
\end{tabular}

Legenda: (1) As concessões de patentes foram tabeladas considerando o campo tecnológico correspondente ao primeiro símbolo de classificação dos pedidos.

N.A.: Não avaliados por não possuírem campo tecnológico correspondente ao símbolo de classificação

Fonte: Adaptado de INPI, (2020). 
Research, Society and Development, v. 10, n. 4, e50210413791, 2021

(CC BY 4.0) | ISSN 2525-3409 | DOI: http://dx.doi.org/10.33448/rsd-v10i4.13791

Tabela 17: Modelo de utilidade - Aplicações para os 10 maiores escritórios.

\begin{tabular}{|c|c|c|c|c|c|c|c|c|c|c|c|c|c|c|c|c|c|c|}
\hline & Dpi: & Escritorio & Origem & 2004 & 2005 & 2006 & 2007 & 2008 & 2009 & 2010 & 2011 & 2012 & 2013 & 2014 & 2015 & 2016 & 2017 & 2018 \\
\hline 1 & Modelo utilitário & Brasil & Total & 3595 & 3230 & 3182 & 3038 & 3382 & 3378 & 2989 & 3080 & 2987 & 3032 & 2734 & 2718 & 2936 & 2918 & 2587 \\
\hline 2 & Modelo utilizário & China & Total & 112825 & 139566 & 161366 & 181324 & 2255586 & 310771 & 409836 & 585467 & 740290 & 892362 & 868511 & $11275 ? 7$ & 1475977 & 1687593 & 2072311 \\
\hline 3 & Modelo utilitário & Alemanha & Total & 20286 & 20498 & 19766 & 18083 & 17067 & 17306 & 17005 & 16024 & 15497 & 15470 & 14741 & 14274 & 14030 & 13301 & 12307 \\
\hline 4 & Modelo utilitärio & Japăo & Total & 7986 & 11387 & 10965 & 10315 & 9452 & 9507 & 8679 & 7984 & 8112 & 7622 & 7095 & 6860 & 6480 & 8105 & 5388 \\
\hline 5 & Modelo utilitário & Repúbisca da Coreia & Total & 37753 & 37175 & 32908 & 21084 & 17405 & 17144 & 13661 & 11854 & 12424 & 10968 & 9184 & 8711 & 7767 & 6811 & 6232 \\
\hline 6 & Modelo utilizáno & Russia & Total & 8948 & 9473 & 9699 & 10075 & 10995 & 11153 & 12262 & 13241 & 14069 & 14358 & 13952 & 11906 & 11112 & 10643 & 9747 \\
\hline 7 & Modelo utilitário & Espanha & Total & 2904 & 2855 & 2824 & 2666 & 2682 & 2560 & 2640 & 2588 & 2539 & 2648 & 2712 & 2354 & 2439 & 2465 & 2731 \\
\hline 8 & Modelo utilitario & Tailandia & Total: & 1454 & 1652 & 2062 & 1435 & 1515 & 1467 & 1328 & 1342 & 1486 & 1609 & 1748 & 2164 & 2571 & 2517 & 2969 \\
\hline 9 & Modelo utilitârio & Turquia & Total & & & & 3011 & 2992 & 2882 & 3033 & 3280 & 3788 & 3553 & 3569 & 3583 & 3534 & 3320 & 2770 \\
\hline 10 & Modelo utititátio & Uorania & Total & 5232 & 7288 & 8171 & & 9600 & 9205 & 10885 & 10431 & 10217 & 10181 & 9384 & 8616 & 9584 & 9108 & 9120 \\
\hline
\end{tabular}

Fonte: WIPO (2020). 
Além disso, observa-se que nos escritórios do Brasil, Alemanha e Japão ocorreu um decréscimo dos números de aplicações. E os escritórios da República da Coreia, Rússia e Turquia aumentaram as aplicações por um período, porém finalizou o ano de 2018 com resultado menor que no ano de 2004. Já os escritórios da Tailândia e da Ucrânia cresceram de 2004 a 2018 as aplicações de MU feitas. Foi possível perceber ainda, com a análise dos dados da Tabela 17, que nos anos de 2004 a 2006 não foi computado nenhum dado de aplicação no escritório da Turquia e em 2006 no escritório da Ucrânia.

Referente à Tabela 17 a Alemanha, República da Coreia e Rússia reduziram significativamente a quantidade de aplicações de modelo de utilidade de 2004 até 2018. Sendo assim, é possível perceber que a China foi o país com maior desenvolvimento e crescimento de patentes entre os anos de 2004 a 2018. Além disso, é importante ressaltar que os escritórios da Tailândia e da Ucrânia, apesar de apresentarem menores valores de aplicações de patentes, aumentaram suas aplicações de patentes durante o mesmo período.

Além da representação numérica expressa na Tabela 17 o banco de dados da WIPO apresenta outras opções de exibição de dados. Para melhor visualização e entendimento dos dados escolheu-se o gráfico tipo pizza para expressar os dados em porcentagem. O gráfico da Figura 2 apresenta os resultados das aplicações de MU feitas nos 10 maiores escritórios entre os anos de 2004 a 2018.

Figura 2: Representação gráfica da porcentagem de aplicações feitas por escritório nos anos de 2004 a 2018.

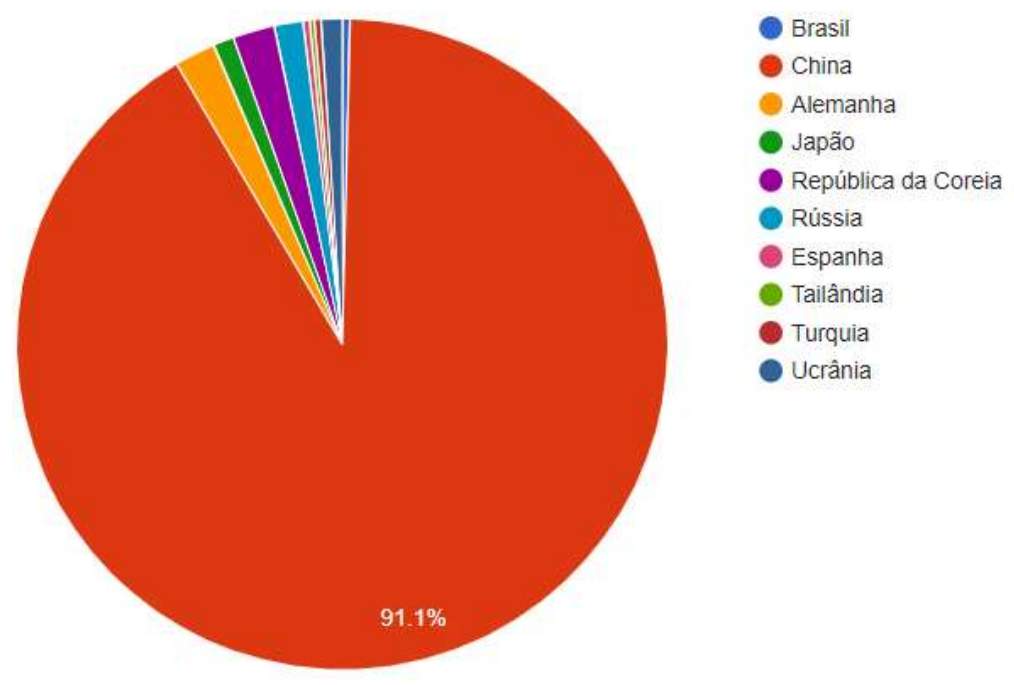

Fonte: WIPO (2020).

Segundo a Figura 2 houve um crescimento significativo do número de patentes aplicadas no escritório da China no período de 2004 a 2018, representando 91,1\% em comparação aos demais países. Em contrapartida, os demais países tiveram resultados variados de um ano para outro. Para as aplicações de patentes, o Brasil também está entre os 20 maiores escritórios do mundo. Conforme a Figura 3, a China também foi o escritório que teve mais destaque em comparação aos outros países. 
Figura 3: Representação gráfica da porcentagem das aplicações feitas por escritório nos anos de 2004 a 2018.

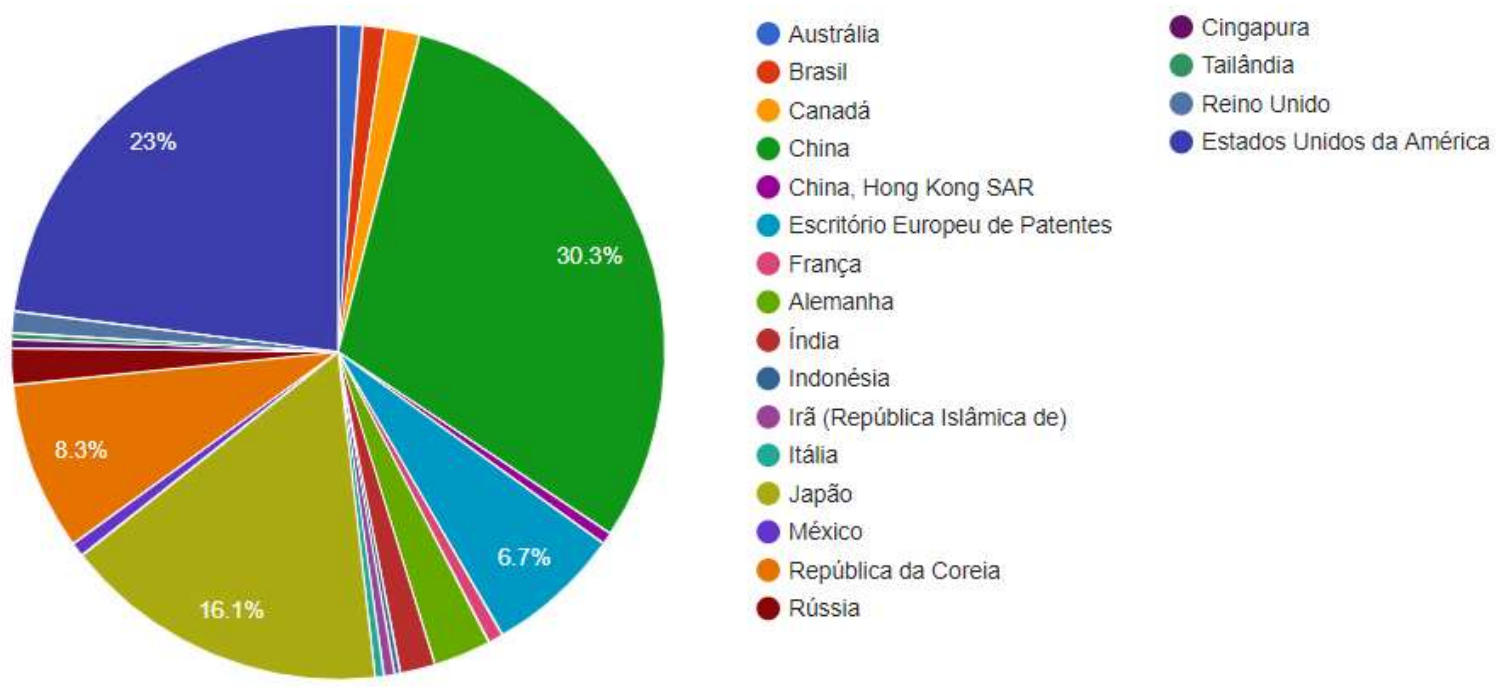

Fonte: WIPO (2020).

\section{Considerações Finais}

O presente estudo buscou apresentar a evolução dos depósitos de patentes no período de 2000 a 2018, a fim de demonstrar o cenário quantitativo dos requerimentos e concessões de PI, MU e CA no Brasil, por meio do levantamento dos dados obtidos nas bases do INPI e WIPO. Na análise comparativa dos dados evidenciou-se a predominância dos depósitos das patentes por não residentes, revelando a importância dos investimentos das multinacionais no país. Em relação aos depositantes residentes, os maiores responsáveis são as Universidades e as Instituições Públicas. Ainda, foi possível observar que, na combinação por tipo e natureza jurídica, as pessoas jurídicas vêm apresentando uma maior participação nas patentes de invenção, enquanto, para os MU e CA as pessoas físicas ainda exercem predomínio. Em relação às vias de entrada, pôde-se verificar a variação de acordo com o tipo, sendo os depósitos de PI mais requeridos por entrada via PCT, e os MU diretamente no INPI. No campo tecnológico, denota-se que a Química Orgânica Fina, Produtos Farmacêuticos, Tecnologia Médica, Química de Materiais Básicos e Tecnologia destacam-se à frente nos depósitos das PI. Para os MU, sobressaem-se Móveis, Jogos, Engenharia Civil, Outras Máquinas Especiais, Manejo e Outros Bens de Consumo como maiores responsáveis. Com relação às aplicações de MU nos 10 maiores escritórios do mundo e as aplicações de patentes dos 20 maiores escritórios no período de 2004 a 2018, verificou-se que o Brasil está inserido nesse grupo, no entanto, a China é o país que mais vem apontando o desenvolvimento e crescimento de patentes no período. Conclui-se que o Brasil tem relevância significativa na área de Propriedade Industrial. Apesar dessa importância percebe-se que o número de depósito em relação ao número de concessões, é bem maior. Segundo o Relatório de Atividade do INPI de 2019, o Plano de Combate ao Backlog, implementado em 2018, visa diminuir em 80\%, até 2021, a quantidade de pedidos com exame requerido e pendentes de decisão.

Espera-se que os indicadores demonstrados na presente pesquisa possam contribuir com estudos adicionais a fim de traçar o perfil dos depositantes e comportamento dos depósitos de patentes no Brasil. Assim, os autores sugerem que novas pesquisas sejam realizadas sobre o tema, com intuito de se verificar os novos índices de patentes depositadas e concedidas no Brasil.

O trabalho atual representa um recorte temporal no intervalo de tempo em que foi possível obter dados comparáveis entre as duas bases estudadas (2000-2018). Trabalhos futuros devem englobar atualizações nos dados obtidos neste artigo, assim que disponibilizados e explorar outras bases de dados. 
Research, Society and Development, v. 10, n. 4, e50210413791, 2021

(CC BY 4.0) | ISSN 2525-3409 | DOI: http://dx.doi.org/10.33448/rsd-v10i4.13791

\title{
Agradecimentos
}

\author{
Agradecemos a FAPEMIG, CNPq e CAPES.
}

\section{Referências}

BRASIL (1970). Presidência da República. Casa Civil. Subchefia para Assuntos Jurídicos. Lei no 5.648, de 11 de dezembro de 1970. Cria o Instituto Nacional da Propriedade Industrial e dá outras providências. http://www.planalto.gov.br/ccivil_03/leis/15648.htm.

BRASIL (1996). Presidência da República. Casa Civil. Subchefia para Assuntos Jurídicos. Lei nº 9.279, de 14 de maio de 1996. Regula direitos e obrigações relativos à propriedade industrial. http://www.planalto.gov.br/ccivil_03/leis/19279.htm.

Campos, A. C. \& Denig, E. A. (2011). Propriedade intelectual: uma análise a partir da evolução das patentes no Brasil. Revista Faz Ciência, 18, 97-120. Dias, M. M. (2008). Parameters of choice for data mining tools and techniques. Acta Scientiarum. Technology, 24, $1715-1725$.

https://doi.org/10.4025/actascitechnol.v24i0.2549

FAPESP (2011). Indicadores de ciência, tecnologia e inovação em São Paulo 2010. Volume I. São Paulo.

Ferreira, V.V.R. (2018). A valorização das patentes na área de Química. Dissertação, Universidade Federal do Triângulo Mineiro, Uberaba, http://bdtd.uftm.edu.br/handle/tede/617

Gil, A. C. (2017). Como elaborar projetos de pesquisa. (6. Ed.). Atlas.

Instituto Nacional de Propriedade Industrial (2019). Rumo à excelência: relatório de atividades 2019. https://www.gov.br/inpi/pt-br/central-deconteudo/publicacoes/arquivos/relatorio-de-atividades-inpi_2019.pdf.

Instituto Nacional de Propriedade Industrial (2020). Indicadores de Propriedade Industrial 2019: o uso do sistema de propriedade industrial no Brasil. https://www.gov.br/inpi/pt-br/acesso-a-informacao/pasta-X/boletim-mensal/arquivos/documentos/indicadores-de-pi_2019.pdf.

Instituto Nacional de Propriedade Industrial (2020). Patentes. <https://www.gov.br/inpi/pt-br/servicos/perguntas-frequentes/patentes\#tipos>

Khan, M. \& Dernis, H. (2006). Global overview of innovative activities from the patent indicators perspective. OECD Science, Technology and Industry Working Papers, 2006. https://www.oecd-ilibrary.org/docserver/674714465672.pdf?expires=1609950455\&id=id\&accname=guest\&checksum= 17456913ED81BD0F41AD87BAC9DBD7CC.

Ministério da Ciência e Tecnologia DA INOVAÇÃO (2019). Patentes - INPI - Escritório Brasileiro.

http://antigo.mctic.gov.br/mctic/opencms/indicadores/detalhe/Patentes/INPI/6.1.2.html.

Organização Mundial da Propriedade Intelectual. (2016) Instituto Nacional da Propriedade Industrial. Módulo 7: patentes. Brasil: OMPI: INPI, 2016. Ribeiro, L., Paiva, L. \& Loureiro, I. (2010). Monitoramento tecnológico: um estudo sobre as patentes depositadas no Brasil entre 2006 e 2008. Rio de Janeiro: Inmetro/Ditec, 2010. Relatório técnico. http://www.inmetro.gov.br/inovacao/pdf/monitoramento-tecnologico.pdf.

Romão, W. (2002). Descoberta de conhecimento relevante em banco de dados sobre ciência e tecnologia. Tese (Doutorado em Engenharia de Produção). Universidade Federal de Santa Catarina.

Silva, A.C.R. da, de Almeida, M.S., Favaro, M.A.S.C.N., Malpass, G.R.P. \& Granato, A. C. (2019). Análise científica e tecnológica sobre dengue e h1n1: comparativo entre doença tropical negligenciada e não negligenciada. Revista Brasileira De Inovação Tecnológica Em Saúde, 9(1), 57-73. 10.18816/rbits.v1i9.15834

Sousa, D.N., Okura, M.H., Scatena, L.M., Malpass, G.R.P. \& Granato, A.C. (2018). Survey of patents involving the plant Moringa oleifera Revista Brasileira de Ciência, Tecnologia e Inovação, 3(1), 79-90. 10.18554/rbcti.v3i1.3150

World Intellectual Property Organization (2017). WIPO: Making IP Work. Geneva: WIPO.

https://www.wipo.int/edocs/pubdocs/en/general/1060/wipo_pub_1060.pdf.

World Intellectual Property Organization (2020). WIPO IP Statistics Data Center. Geneva: WIPO. https://www3.wipo.int/ipstats/keysearch.htm?keyId=231.

World Intellectual Property Organization. (2001) Tratado de Cooperação em matéria de Patentes (PCT). Washington: WIPO. 